\title{
Comparing and Contrasting the Multiple Roles of Butenolide Plant Growth Regulators: Strigolactones and Karrikins in Plant Development and Adaptation to Abiotic Stresses
}

\author{
Tao Yang ${ }^{\dagger}$, Yuke Lian ${ }^{\dagger}$ and Chongying Wang * \\ Ministry of Education Key Laboratory of Cell Activities and Stress Adaptations, School of Life Sciences, \\ Lanzhou University, Lanzhou 730000, China; yangtao@lzu.edu.cn (T.Y.); lianyk18@lzu.edu.cn (Y.L.) \\ * Correspondence: wangcy@lzu.edu.cn; Tel.: +86-0931-8914155; Fax: +86-0931-8914155 \\ + These authors contributed equally to this work.
}

Received: 24 November 2019; Accepted: 10 December 2019; Published: 12 December 2019

\begin{abstract}
Strigolactones (SLs) and karrikins (KARs) are both butenolide molecules that play essential roles in plant growth and development. SLs are phytohormones, with SLs having known functions within the plant they are produced in, while KARs are found in smoke emitted from burning plant matter and affect seeds and seedlings in areas of wildfire. It has been suggested that SL and KAR signaling may share similar mechanisms. The $\alpha / \beta$ hydrolases DWARF14 (D14) and KARRIKIN INSENSITIVE 2 (KAI2), which act as receptors of SL and KAR, respectively, both interact with the F-box protein MORE AXILLARY GROWTH 2 (MAX2) in order to target SUPPRESSOR OF MAX2 1 (SMAX1)-LIKE/D53 family members for degradation via the 26S proteasome. Recent reports suggest that SLs and/or KARs are also involved in regulating plant responses and adaptation to various abiotic stresses, particularly nutrient deficiency, drought, salinity, and chilling. There is also crosstalk with other hormone signaling pathways, including auxin, gibberellic acid (GA), abscisic acid (ABA), cytokinin (CK), and ethylene (ET), under normal and abiotic stress conditions. This review briefly covers the biosynthetic and signaling pathways of SLs and KARs, compares their functions in plant growth and development, and reviews the effects of any crosstalk between SLs or KARs and other plant hormones at various stages of plant development. We also focus on the distinct responses, adaptations, and regulatory mechanisms related to SLs and/or KARs in response to various abiotic stresses. The review closes with discussion on ways to gain additional insights into the SL and KAR pathways and the crosstalk between these related phytohormones.
\end{abstract}

Keywords: strigolactone; karrikin; development; abiotic stress; hormonal crosstalk

\section{Introduction}

Environmental constraints, both biotic and abiotic, can deliver deleterious effects to both plant survival and crop productivity [1-3]. Moreover, global climate change threatens greater environmental deterioration and risks the continued sustainability of agriculture [4,5]. Plants have evolved many survival strategies to respond to various adverse environmental conditions, including morphological changes, physiological, biochemical, and molecular responses, including global reprogramming of transcription [2,6-11]. Various phytohormones, such as abscisic acid (ABA), brassinosteroids (BRs), jasmonic acid (JA), salicylic acid (SA), ethylene, and cytokinins (CKs), integrate the signaling needed to cooperatively optimize both plant development and the adaptive responses to environmental stressors [12-19]. Plants are able to alleviate the adverse effects of biotic and abiotic environmental 
factors through interactions between the phytohormone regulatory networks via the perception and signal transduction originating at various receptors [20-23].

Strigolactones (SLs) were originally isolated from root exudates of cotton and as seed germination stimulants from plants in the Orobanchaceae family that parasitize plant roots (Striga, Phelipanche, and Orobanche spp.) [24-26]. SLs normally control seed germination and seedling development [27], shoot branching [28-32], root architecture [33], and leaf senescence [34]. SLs also promote beneficial symbiotic relationships between host plants and mycorrhizal fungi $[35,36]$. The biosynthesis and signaling of SLs are regulated by various abiotic stress factors [37-40], including the recently reported SL involvement in responding to nutrient deprivation, drought, chilling and salinity [38,40-50]. Such studies provide new insights into the novel roles SL signaling plays in the regulation of plant adaptation to adverse environmental conditions [51-54].

Karrikins (KARs) are found in smoke released from the heating or combustion of plant material, after which they can stimulate the germination of dormant seeds [55-58]. KARs are also involved in the inhibition of hypocotyl elongation and in the promotion of cotyledon expansion and seedling vigor [59-61]. KARs are structurally related to SLs and share a common substituted butenolide moiety $[55,59,62]$. Recent studies also provided evidence that KARs have potential functions in mediating abiotic stress tolerance in plants $[8,63,64]$. These finding suggest that KAR molecules may have a similar function to those of SLs in plant adaptation to abiotic stress.

Previous studies and reviews have summarized the biosynthesis, perception and signaling of SLs and KARs $[52,53,65,66]$. In addition, the functions of SL and KAR signaling in the control of plant growth and development have also been described [62]. Numerous studies have particularly focused on the functioning of SLs and KARs in plant responses and adaptation to abiotic stress. Despite a basic structural similarity, KARs and SLs are not interchangeable signals. In this review, we briefly cover their biosynthesis and signaling networks, compare their functions in plant growth and development, and highlight the putative mechanisms by which SLs and/or KARs regulate the response to abiotic stresses. Furthermore, the crosstalk between SLs, KARs and other phytohormones under adverse conditions are also discussed.

\section{Classical Structure and Biosynthesis of SLs and KARs}

SLs are carotenoid-derived phytohormones (Figure 1). Carotenoids are converted by the sequential action of all-trans- $\beta$-carotene isomerase (AtD27 in Arabidopsis and D27 in rice) [67-69], two carotenoid cleavage dioxygenases: [CCD7 (MAX3 in Arabidopsis, RMS5 in Pea, DAD3 in Petunia and HTD1/D17 in rice)] [70-72], and CCD8 (MAX4 in Arabidopsis, RMS1 in Pea, DAD1 in Petunia and D10 in rice) [73-76] into the SL intermediate carlactone (CL) [77]. CL is oxidized by the cytochrome P450 enzyme MAX1 [Carlactone oxidase (Os01g0700900) and orobanchol synthase (Os01g0701400) in rice] [78-80] and subsequently methylated and oxidized by lateral branching oxidoreductase (LBO), which may catalyze the final step in SL-like compound biosynthesis in Arabidopsis [81] (Figure 1).

KARs are small organic chemicals with bioactive compounds identified as butenolides, which are related to chemical 3-methyl-2H-furo[2,3-c]pyran-2-one [55,57,58]. KARs are produced by the pyrolysis of simple carbohydrates, such as xylose, glucose, or cellulose, which can occur during wildfires [82] (Figure 1). To date, six KAR compounds, annotated as $\mathrm{KAR}_{1}$ to $\mathrm{KAR}_{6}$, have been identified in plant-derived smoke and differ in their methyl group substitutions [57]. Among them, $\mathrm{KAR}_{2}$ is commonly used in research due to its higher bioactivity in Arabidopsis compared to other KARs [83]. In general, KARs are stable at room temperature and in aqueous solutions [55,58]. 
A

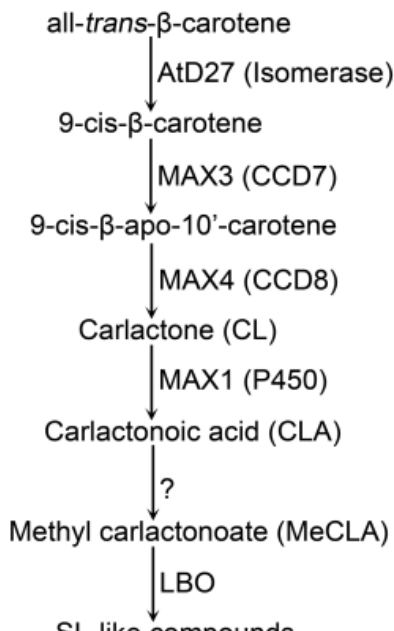

SL-like compounds

B
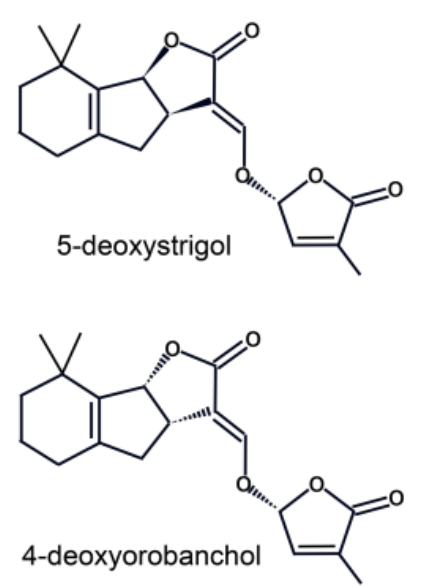

C

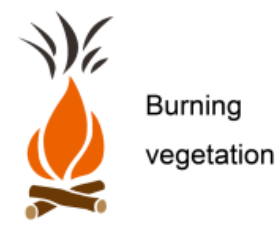

D<smiles>Cc1c2ccocc-2oc1=O</smiles><smiles>O=c1cc2ccocc-2o1</smiles>

$\mathrm{KAR}_{2}$

E<smiles>CCOCCOCCOC1C=C(C)C(=O)O1</smiles><smiles>CC1=CC(=C(C)C)OC1=O</smiles>

Figure 1. Strigolactone (SL) biosynthesis in Arabidopsis and chemical structures of SLs and karrikins (KARs). (A) Proposed model for SL biosynthesis in Arabidopsis. The conversion of carlactone (CL) from all-trans- $\beta$-carotene by the sequential actions of the isomerase AtD27 and the carotenoid cleavage dioxygenases MAX3 and MAX4 in plastids. In the cytosol, CL is converted into SLs via the cytosolic P450 MAX1, LATERAL BRANCHING OXIDOREDUCTASE (LBO) and other unknown enzymes. (B) Structures of two representatives of natural SLs (5-deoxystrigol and 4-deoxyrobanchol). (C) KARs are produced during the burning of vegetation. (D) Structures of the two major KARs $\left(\mathrm{KAR}_{1}\right.$ and $\mathrm{KAR}_{2}$ ). (E) Structures of the commonly used synthetic SL analog rac-GR24, which is a mixture of GR24 $4^{5 \mathrm{DS}}$ and its enantiomer GR24 ${ }^{\text {ent }}$-5DS.

\section{Signal Transductions of SL and KAR}

SLs and KARs belong to the butenolide class of compounds [55,67]. SLs and KARs have similar structures [84] and play roles in the growth and development of plants. Recent, significant breakthroughs have been made that reveal the connection between SL and KAR signal transduction pathways.

Recent crystallization studies have shown how SLs are perceived by D14 (DWARF14), a non-canonical $\alpha / \beta$ hydrolase receptor $[85,86]$. Upon binding, AtD14 docks SL into its catalytic pocket in an "open state" and hydrolyses SL into a hydrolytic D-ring-derived intermediate molecule (D3), which is then covalently and irreversibly sealed inside the closed catalytic cavity of AtD14 [86-88]. The conformation of AtD14-D3 is significantly different than that of AtD14 after the open-to-closed transition, and now interacts with the F-box leucine-rich repeat protein MAX2. The resulting MAX2/RMS4/D3 SCF complex targets the transcriptional repressors D53 (DWARF 53) in rice or SMXL6/7/8 (SUPPRESSOR OF MAX2 1 (SMAX1)-LIKE 6/7/8) in Arabidopsis for degradation via the 
26S proteasome. Removal of D53/SMXL6/7/8 allows SL-based signal transduction, which alters various physiological and biochemical functions [30,32,86,89,90] (Figure 2A).
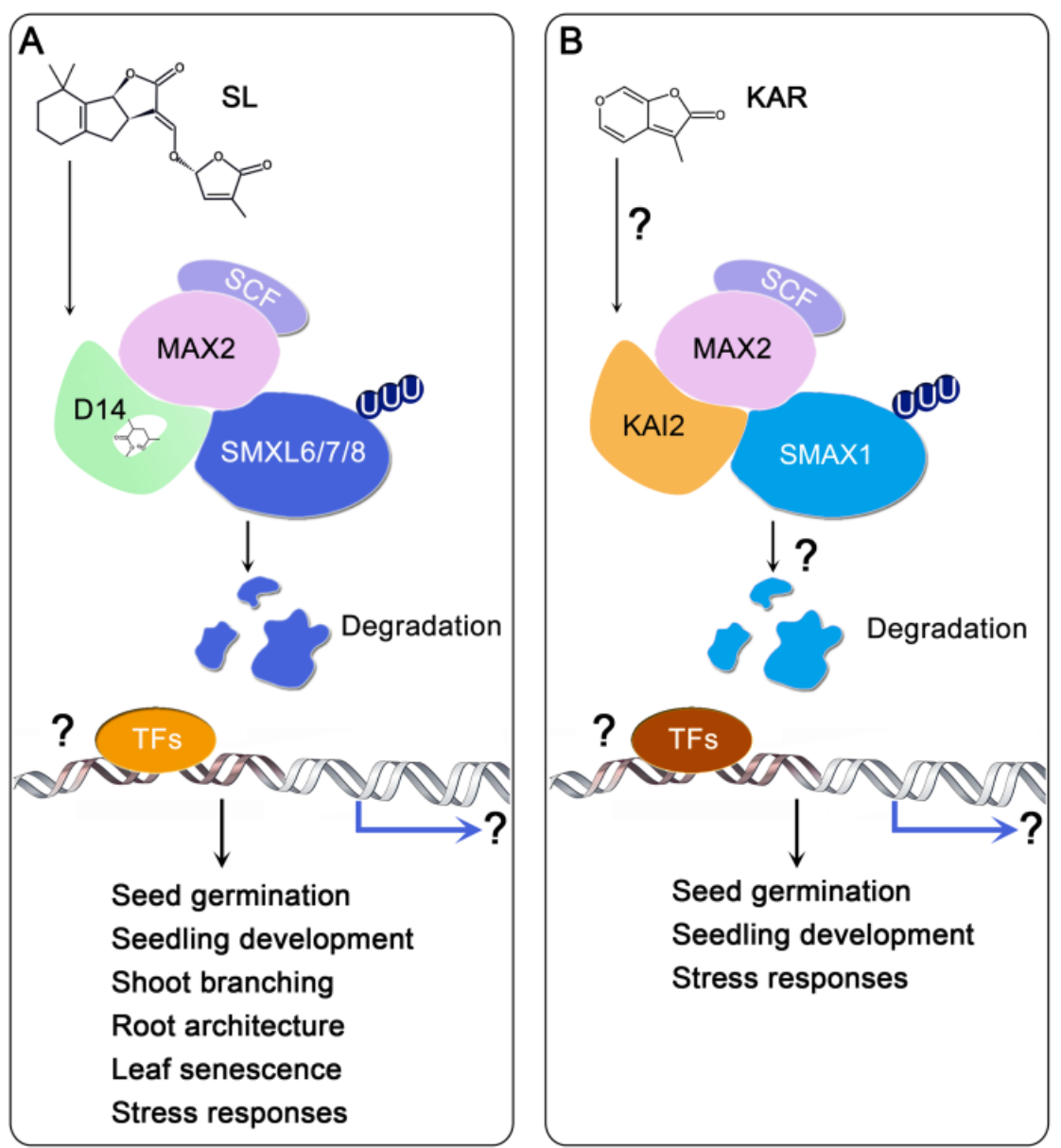

Figure 2. Simplified models of SL signaling and hypothetic KAR signaling. (A) The SL receptor AtD14 binds and hydrolyzes the SL, triggering the formation of a D14-SCF ${ }^{\text {MAX2 }}$-SMXL6/7/8 complex which targets SMXL6/7/8 for ubiquitination and degradation, which then relieves the repression of yet-unknown TFs and activates the expression of downstream targets. (B) KAR or a putative KAI2 ligand is perceived through KAI2. The ligand-receptor interaction triggers the formation of a KAI2-SCF ${ }^{\mathrm{MAX} 2}$-SMXL1 complex to induce the ubiquitination and degradation of SMXL1, which then activates downstream responses. Question marks indicate the undemonstrated hypotheses. SL, strigolactone; KAR, karrikin; D14, DWARF14; MAX2, MORE AXILLARY GROWTH 2; SMAX1, SUPPRESSOR OF MAX2 1; SMXL, SMAX1-LIKE; KAI2, KARRIKIN INSENSITIVE 2; U, ubiquitin; TFs, transcription factors.

The $\alpha / \beta$-fold hydrolase KARRIKIN INSENSITIVE2 (KAI2), which is a paralogue of D14, is characterized as the KAR receptor in Arabidopsis [91]. $\mathrm{KAR}_{1}$ has been demonstrated to bind KAI2 [91,92]. Although KAR signaling mechanisms remain unclear, genetic studies have provided evidence that the KAI2 signal pathway may be similar to that of D14 [84,93,94]. Based on an analogy to SL signaling, the hypothetical signaling for smoke-derived KARs or KAR-like (KL) metabolites initiates with its perception by KAI2, which leads to its interaction with MAX2 and SMXL1 and subsequent formation of a SCF ${ }^{M A X 2}$-KAI2-SMXL1 complex. SMXL1, like SMXL6/7/8 in the SL pathway, is then polyubiquitinated for $26 \mathrm{~S}$ proteasomal degradation, triggering the signaling downstream of the KARs $[28,90]$. However, this proposed KAI2-dependent signaling pathway, including the KAR-mediated interaction among KAI2, MAX2, and SMXL1 and the degradation of SMXL1, remain to be further confirmed (Figure 2B). 
Since the signal transduction pathways following both KAR and SL are both dependent on MAX2, which interacts with both KAI2 and D14, crosstalk between KAR and SL signaling may be observed. In other words, MAX2 may act as a connector between the two different signaling pathways. However, the physiological responses are completely different, possibly because MAX2-dependent signaling can identify the different response signals. Thus, a comparative study of the KAR and SL pathways should be performed in the future to provide a better understanding of the functions of D14 and KAI2 in MAX2-dependent signaling. Although both D14 and KAI2 undergo degradation during signal transduction, there is evidence that the degradation of KAI2 might be dependent on its Ser95, and not on MAX2 or the 26S proteasome, implying that other unidentified components may contribute to the degradation, and possibly downstream signaling, of KAI2 [94,95].

\section{Similarities and Differences Between the Functions of SLs and KARs in Plant Development}

In recent years, numerous lines of evidence have demonstrated that SLs and KARs regulate plant growth and development. Although SLs and KARs have similar chemical structures, plants can still distinguish SL and KAR signaling at various stages of development. Some of the major effects on plant development initiated by SLs and KARs are highlighted below (Figures 3 and 4).

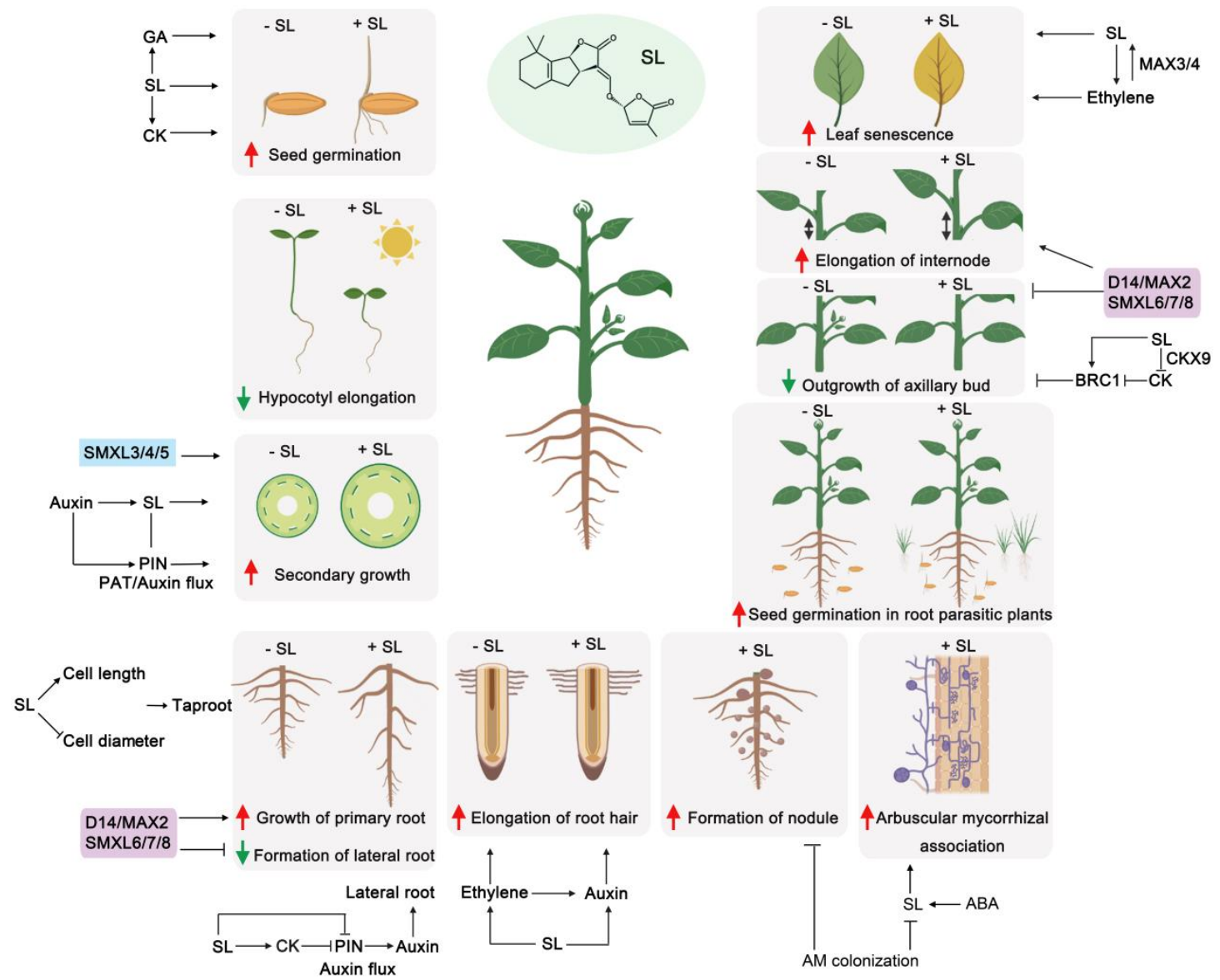

Figure 3. Roles of SLs in plant development. SLs interact with auxin, ABA, CK, GA and ethylene to regulate plant development at different stages. Red arrows represent a promotion effect or positive regulation, and green arrows represent inhibitory effects or negative regulation. GA, gibberellic acid; CK, cytokinins; ABA, abscisic acid. PIN1, PIN-FORMED 1; PAT, polar auxin transport; BRC1, BRANCH 1. 


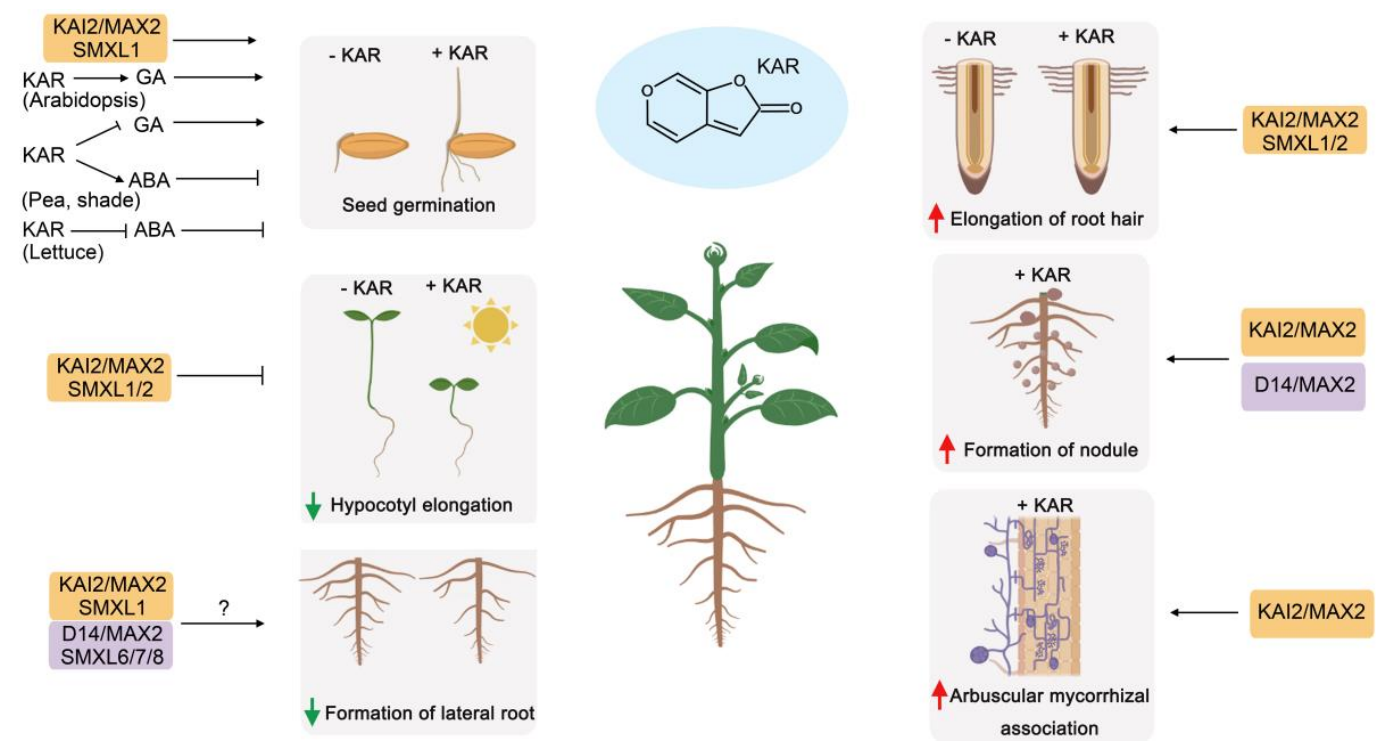

Figure 4. Roles of KARs in plant development. KARs interact with ABA, GA and other hormones to regulate plant development at different stages. Red arrows represent promotion effects/positive regulation, and green arrows represent inhibitory effect/negative regulation. GA, gibberellic acid; ABA, abscisic acid. Question marks (?) represent potential interactions that have not been directly demonstrated.

\subsection{Utilization of Storage Reserves in the Early Seed Germination}

Seeds sense endogenous and environmental signals such as endogenous storage reserves, air, oxygen, temperature, water, light, or darkness to determine whether they are suitable for germination. These signals may play important roles in promoting or inhibiting germination. Chemical germination signals derived from smoke have attracted much attention due to their significant effects on the seed germination of many plants. Wildfire smoke contains certain potent bioactive compounds including $\mathrm{KAR}_{1}$, trimethylbutenolide (TMB) and smoke-water (SW). In particular, KAR may modulate the early seed germination by influencing the activity of hydrolase and contents of lipids, protein, carbohydrate, and starch during seed germination. In Lactuca sativa seeds, $\mathrm{KAR}_{1}$ and $\mathrm{SW}$ treatments enhance $\alpha$-amylase activity in dark and FR light, however, TMB inhibits $\alpha$-amylase activity in all light treatments. Similarly, $\mathrm{KAR}_{1}$ improves the contents of lipids, protein, carbohydrate, and starch, while TMB plays an opposite role in the early seed germination. These data suggest that the mobilization and utilization of storage reserves are improved after applying $\mathrm{KAR}_{1}$ and SW, and then, enough energy is provided for the germination of the seeds [96].

\subsection{Seed Germination}

Both SLs and KARs have been found to stimulate seed germination. The difference is that SLs are mainly secreted into the soil by the plant roots and end up stimulating the germination of parasitic plant seeds or transported upward through the xylem to the aboveground parts, while KARs are found in the smoke arising from fire and can then promote the germination of seeds on the ground after the fire $[55,67]$. SLs can alleviate the inhibition of seed germination by heat through regulating GA and ABA levels [97]. In addition to promoting the germination of parasitic plant seeds, SLs also inhibit Physcomitrella spore germination [98].

KARs can promote the light response during seed germination [83,99]. Surprisingly, KARs can delay soybean seed germination under shaded conditions, but not in the dark or under white light, by regulating the biosynthesis of ABA and GA [100]. A recent study in lettuce demonstrated that SW and $\mathrm{KAR}_{1}$ promote seed germination through decreasing the ABA content and enhancing the 
hydrolase activity, however, the $\mathrm{KAR}_{1}$-related compound TMB inhibits the germination of lettuce seeds by increasing ABA and inhibiting cytokinin contents under dark conditions [96].

\subsection{Leaf Morphogenesis}

Both SLs and KARs are involved in the regulation of leaf shape. Arabidopsis lines lacking SL signaling due to mutation of max or $d 14$ had a reduced petiole and leaf aspect ratio and smaller and rounder leaves in comparison with the wild type $[90,101]$. Conversely, the leaf aspect ratio of the smxl6/7/8 triple mutant was increased, and the max 2 leaf phenotypes were restored by mutation of $S M X L 6 / 7 / 8$. Although no effect on the petiole of KAR2 and SMAX1 was detected, reduced blade width and length were observed in smax1max 2 and smax1smx16,7max2 mutant plants compared with max 2 or smxl6,7max 2 mutant plants. The phenotypic analysis of Arabidopsis leaves suggested that $s m x 16 / 7 / 8$, smax 1 and their respective receptor mutants may perform opposite functions in leaf morphology [28,90].

\subsection{Shoot Branching}

There are many pieces of evidence for the involvement of SLs in branching. SL-related mutants exhibit an increased branching or tillering phenotype. For example, the high-branching/tillering phenotypes of SL synthetic mutants (max1, max3, and max4; dad1 and dad3; rms1 and rms5; d10, d17/htd1 and $d 27$ ) are restored by the exogenous application of SLs. However, the phenotypes of SL response mutants (max2, dad2, rms4, $d 3$ and d14) could not be restored with SL application [29,102,103]. Recently, exogenous SLs were shown to inhibit outgrowth of axillary buds in apple (Malus spectabilis) [104]. SLs secreted by roots suppress plant branching mainly through upward transport to axillary buds [105]. In rice, mutation of D53, which is normally a repressor of the SL signal pathway, is a gain-of-function mutant with a multi-branching phenotype. A triple mutant of SMXL6/7/8, homologous proteins of D53 in Arabidopsis, exhibited a reduced branching phenotype. In addition, the multi-branched phenotype of max 2 can be restored in a smxl6/7/8 mutant background, suggesting that D53-like SMXLs regulate shoot branching in a MAX2-dependent manner [89,90]. IPA1 (ideal plant architecture 1) acts as a targeted transcription factor downstream of D53 and is involved in the regulation of SL-mediated tillering and D53 expression in rice [106].

SLs also regulate the development of bryophytes, such as promoting spore germination and branching [107]. In Petunia hybrida, an ABC protein PaPDR1 (Petunia axillaris PLEIOTROPIC DRUG RESISTANCE 1) acts as a transporter of SLs and regulates symbiotic signaling and branching. Increased branching and reduced symbiotic interactions were observed in the pdr1 mutant, which was caused by impaired SL allocation due to defective SL exudation [108]. NtPDR6 (Nicotiana tabacum PLEIOTROPIC DRUG RESISTANCE 6) is a homologous protein of PaPDR1 and plays a key role in regulating plant branching [109], indicating that the transport of SLs may be similar in different plants.

The regulation of branching by SLs first involves the interaction with other plant hormones (see the following hormone section for details). Secondly, SLs influence the branching of plants by regulating the branching-related genes, including the TCP transcription factors BRANCH1 (BRC1) in tomato, Arabidopsis, pea and potato, FINECULM1 (FC1) in rice, and TEOSINTE BRANCHED1 (TB1) in teosinte and maize [110-114]. SLs also play important regulatory roles in secondary growth of dicotyledonous plants. SL promotes stem secondary growth by affecting cambial cell division and inducing specific genes. For instance, expression of the MAX2 gene under a cambium-specific (WOX4) promoter could restore the secondary growth defect of the max 2 mutant [115]. More recently, a study reported that SL is required for shoot elongation by its mediation of gibberellin metabolism and signaling in rice [116].

To date, there is no evidence that KARs can regulate the branching of plants. Any discovery of KAR signaling-related mutants may help to explore whether KAR functions in regulating plant branching. 


\subsection{Root System Development}

Numerous studies have revealed that SLs are involved in the regulation of root development. SLs promote the elongation of the primary root and root hairs and inhibit the formation of the lateral root in Arabidopsis [33,117]. For example, a shortened taproot was observed in the SL-deficient $c c d 8$ mutant in pea seedlings. In rice SL-deficient mutant, the distinct root-cap was reduced, which could be restored by application of SLs $[118,119]$. SLs also inhibit adventitious root formation in Arabidopsis, tomato, and pea [120-122]. Recent research shows that SLs induce the presence of hypodermal passage cells (HPC) in Petunia roots, which may play a role in regulating water and nutrient exchange between the root and the soil. Further study showed that this process depends on the KAI2/MAX2 pathway, suggesting that SLs and KARs play roles in the appearance of HPC [123].

A recent study demonstrated that KAI2 signaling is an important regulator of root hair and root development in Arabidopsis, mainly through the KAI2-SMAX1/2 pathway [124]. Interestingly, SL and KAR signaling together control the density of lateral roots, while most root traits, including root growth direction, root straightness and root hair development, are determined by KAR signaling alone. This finding provides new evidence for dissecting the different roles of SL and KAR signaling in root and root hair development.

\subsection{Mycorrhizal Symbiosis}

Most terrestrial plants can form symbiotic relationships with arbuscular mycorrhiza. SLs are rhizosphere signals that are recognized by AM, which lead to the germination of spores and the formation of mycelial branches $[35,125,126]$. One of the most important functions of SLs is this promotion of symbiosis with AM. The synthetic SL GR24 is used as a root drench to promote the difficult colonization with arbuscular mycorrhiza and eventual formation of symbiosis [108,127]. GR24 enhances mycorrhizal colonization in rice, petunia, and pea $[29,128]$. After arbuscular mycorrhizal colonization, the level of SLs decreased in tomato [129]. Similarly, the colonization of pea by arbuscular mycorrhizal resulted in a decrease in the germination rate of parasitic seeds due to a decrease in the content of SLs [130]. Moreover, arbuscular mycorrhizal colonization may inhibit the formation of legume nodules, due to the decrease in SL content [131]. For example, the root exudates of the SL-deficient $r m s 1$ mutant in pea have lower SL content and reduced nodulation capacity compared with the wild type, suggesting that SLs, as positive regulators of nodulation in peas, are necessary for optimal nodulation [118]. A recent study shows that GmMAX2-mediated SL and KAR signaling are involved in regulating soybean-rhizobia interaction and nodulation through interactions with auxin and JA hormones [132].

In Arabidopsis, KARs induced seed germination, inhibited hypocotyl elongation, and promoted cotyledon opening. The germination of a KAR mutant was not alleviated by application of KARs [56]. DWARF14-LIKE (D14L) is homologous to KAI2 and co-participates in the regulation of MAX2-dependent KAR signaling pathways [91,133]. The hebiba mutant lost its ability to respond to arbuscular mycorrhizal fungi in rice, and D14L may be responsible for this loss of symbiosis, suggesting that KAR receptor complexes are involved in the perception of arbuscular mycorrhizal fungi in rice [134].

While SLs and KARs have similar molecular structures and produce similar effects in some ways, plant responses to SLs and KARs also differ in several aspects. For instance, both GR24 and KARs inhibit the light-regulated elongation of the hypocotyl [99]. The inhibition of hypocotyl elongation by MAX2- and light-dependent SL signals is mainly achieved by cryptochrome and phytochrome signaling pathways, among which the regulatory factors mainly include COP1, HY5, and PIFs [135]. On the other hand, SLs promote the germination of parasitic seeds, while KARs cannot, but KAR has a stronger influence on non-parasitic plant seed germination than GR24 [83,136]. In Arabidopsis, D14 mainly affects branch formation, leaf morphological development and root development of mature plants, but has no effect on seed germination $[133,137]$. However, KAI2 regulates seed germination, hypocotyl growth, and cotyledon opening, but does not play a significant role in plant branching [133]. 
In addition to the D14 and KAI2 proteins, there is a D14-like protein, DLK2, but it does not respond to any of the SL or KAR signals [133].

\section{Hormone Interactions During SL- or KAR-Mediated Plant Development}

Recent studies have shown that SLs can cooperate with or antagonize other plant hormones during plant development and biotic and abiotic stresses. Similarly, KARs may work with many plant hormones (Figures 3 and 4, Table 1). 
Table 1. Mutations of strigolactone (SL) and karrikin (KAR)-related genes that alter the effects in the growth and development of various plants species.

\begin{tabular}{|c|c|c|c|c|c|}
\hline Species & Mutants & Effects of Mutant & Functions & $\begin{array}{c}\text { Interactions with } \\
\text { Phytohormones }\end{array}$ & References \\
\hline Rice & $d 3, d 14$ and $d 53$ & \multirow{5}{*}{ Increased branching } & $\begin{array}{l}\text { D53 acts as a repressor of the SL signaling to } \\
\text { promoting axillary bud outgrowth }\end{array}$ & & [89] \\
\hline pea & $c c d 8$ & & Endogenous SLs inhibit shoot branching in plants & & [102] \\
\hline pea & ramosus (rms) & & \multirow{3}{*}{ SLs regulate shoot branching } & & [76] \\
\hline Arabidopsis & $\max 4$ & & & & \\
\hline petunia & dad & & & & [138] \\
\hline & ipa1 & Regulated tiller number & $\begin{array}{l}\text { IPA1 interacts with D53 to mediate tiller regulated } \\
\text { by SL }\end{array}$ & & [106] \\
\hline \multirow{5}{*}{ Arabidopsis } & $\max 1$ and $\max 2$ & $\begin{array}{l}\text { Increased branching, round leaves, } \\
\text { elongated hypocotyl }\end{array}$ & $\begin{array}{l}\text { MAX1 and MAX2 control shoot branching by } \\
\text { repressing primordia formation of the } \\
\text { axillary meristem }\end{array}$ & & [101] \\
\hline & \multirow[t]{3}{*}{ 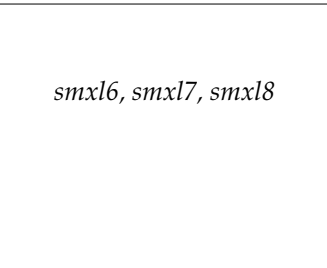 } & Reduced shoot branching in $s m x l 6 / 7 / 8$ & $\begin{array}{l}\text { SMXL6, SMXL7, and SMXL8 promote shoot } \\
\text { branching by repressing BRC1/TCP18 expression } \\
\text { in axillary buds }\end{array}$ & \multirow[t]{3}{*}{ Auxin } & \multirow{4}{*}{ [90] } \\
\hline & & Reduced auxin transport in $s m x 16 / 7 / 8$ & $\begin{array}{l}\text { SMXL6, SMXL7, and SMXL8 promote auxin } \\
\text { transport in a MAX2-dependent manner }\end{array}$ & & \\
\hline & & $\begin{array}{c}\text { Lower lateral root density in } s m x l 6 / 7 / 8 \\
\text { Reduced auxin transport in } s m x l 6 / / 8\end{array}$ & $\begin{array}{l}\text { SMXL6, SMXL7, and SMXL8 promote lateral } \\
\text { root density }\end{array}$ & & \\
\hline & $\begin{array}{l}\text { smxl6, smxl7, smxl8, max } 2 \\
\text { smax1, d14 and kai2 }\end{array}$ & $\begin{array}{c}\text { In short day: elongated petiole in } \\
\text { smxl6//8, shortened petiole in max } 2 \\
\text { and } d 14 \text {, increased both blade length } \\
\text { and width in kai2 }\end{array}$ & $\begin{array}{l}\text { SMAX1 and SMXL6,7,8 regulate the } \\
\text { complementary aspects of leaf morphology in } \\
\text { different signaling pathways }\end{array}$ & & \\
\hline
\end{tabular}


Table 1. Cont.

\begin{tabular}{|c|c|c|c|c|c|}
\hline Species & Mutants & Effects of Mutant & Functions & $\begin{array}{l}\text { Interactions with } \\
\text { Phytohormones }\end{array}$ & References \\
\hline \multirow{5}{*}{ petunia } & $p d r 1$ & Increased branching & $\begin{array}{l}\text { PaPDR1 acts as a transporter of SL to } \\
\text { regulate branching }\end{array}$ & & [108] \\
\hline & \multirow{4}{*}{ dad1/Phccd8 } & Increased branching & $\begin{array}{l}\text { Mutations of } P h C C D 8 \text { caused a high branching } \\
\text { of } d a d 1\end{array}$ & & \multirow{4}{*}{ [75] } \\
\hline & & Smaller flowers & \multirow{3}{*}{$\begin{array}{l}\text { Loss of Dad1 reduces the overall height of the } \\
\text { plant, root and flowering development }\end{array}$} & & \\
\hline & & Reduced internode length & & & \\
\hline & & Reduced root growth & & & \\
\hline Arabidopsis & ore $9 / \max 2$ & \multirow[t]{2}{*}{ Delayed senescence of leaves } & $\begin{array}{c}\text { Dad1/PhCCD8 and ORE9/MAX2 regulate the leaf } \\
\text { senescence by affecting the same } \\
\text { signaling pathway }\end{array}$ & & \multirow[t]{2}{*}{ [101] } \\
\hline Rice & d17 and D10 & & SLs affect leaf senescence & & \\
\hline Arabidopsis & $\max 1, \max 2, \operatorname{pin} 1$ and $\operatorname{pin} 3$ & Reduced cambium activity & $\begin{array}{l}\text { SLs stimulate the secondary growth in } \\
\text { auxin-dependent }\end{array}$ & Auxin & [115] \\
\hline Arabidopsis & $\max 4$ & Reduced auxin content in the leaf & SLs reduce the content of auxin & Auxin & [33] \\
\hline Arabidopsis & $\begin{array}{l}\text { max2, } \max 4 \text { and } \\
\text { pin3pin4pin7 }\end{array}$ & $\begin{array}{l}\text { pin } 3 / 4 / 7 \text { was restored high branching of } \\
\text { max2 and } \max 4\end{array}$ & $\begin{array}{l}\text { PIN3, 4, and } 5 \text { of CAT contribute to branching } \\
\text { mediated by SL }\end{array}$ & Auxin & [139] \\
\hline Arabidopsis & $\max 1-4, i p t 1,5,7$ and ahk 3,4 & \multirow[t]{2}{*}{ Increased adventitious roots } & $\begin{array}{l}\text { SLs suppress adventitious root formation, } \\
\text { SLs could partially restore the stimulating effect of } \\
\text { auxin on adventitious root formation }\end{array}$ & Auxin & \multirow[t]{2}{*}{ [120] } \\
\hline Pea & rms1, rms4 and rms5 & & $\begin{array}{l}\text { SLs also suppress the adventitious root by } \\
\text { reducing the size of rooting zone in Pea }\end{array}$ & & \\
\hline \multirow[t]{2}{*}{ Rice } & $d 3, d 10, d 14$ & $\begin{array}{l}\text { Higher epi-5DS levels by feedback } \\
\text { relationship of SL pathway }\end{array}$ & $\begin{array}{l}\mathrm{GA}_{3} \text { regulates SL biosynthesis in a D3 and D14 } \\
\text { independent manner }\end{array}$ & \multirow[t]{2}{*}{ GA } & \multirow[t]{2}{*}{ [140] } \\
\hline & slr1-5, gid1-3, and gid2-2 & Reduced the levels of SLs & $\begin{array}{l}\text { GAs negatively regulates the level of SLs in a } \\
\text { GID1- and GID2-dependent manner }\end{array}$ & & \\
\hline
\end{tabular}


Table 1. Cont.

\begin{tabular}{|c|c|c|c|c|c|}
\hline Species & Mutants & Effects of Mutant & Functions & $\begin{array}{c}\text { Interactions with } \\
\text { Phytohormones }\end{array}$ & References \\
\hline Species & Mutants & Effects of mutant & Functions & $\begin{array}{l}\text { Interactions with } \\
\text { phytohormones }\end{array}$ & References \\
\hline Maize & up14 & \multirow{2}{*}{ Reduced content of SL in root secretion } & \multirow{2}{*}{ ABA and SL affect each other's synthesis } & \multirow{3}{*}{ ABA } & [141] \\
\hline tomato & notabilis and sitiens & & & & \\
\hline Arabidopsis & $\max$ & Lower sensitivity to $\mathrm{ABA}$ & The synthesis of SL is regulated by ABA & & [41] \\
\hline \multirow[t]{2}{*}{ Arabidopsis } & $\max 1$ and $\max 2$ & Reduced seed germination & $\begin{array}{l}\text { Application of GR24 can restore thermoinhibition } \\
\text { in max1 and max } 2 \text { caused by ABA inhibition of GA } \\
\text { synthesis and signal and increase } \mathrm{GA}_{4} \text { content }\end{array}$ & $\mathrm{ABA}$ and $\mathrm{GA}$ & [97] \\
\hline & $\max 2$ & Lower sensitivity to ABA & $\begin{array}{l}\text { MAX2 participates in ABA signaling pathway as } \\
\text { an important component of SL signaling pathway }\end{array}$ & $\mathrm{ABA}$ & [142] \\
\hline Lotus japonicus & $l j c c d 7$ & Decreased ABA content & $\begin{array}{l}\text { SLs interaction with ABA to regulate the } \\
\text { abiotic stress }\end{array}$ & $\mathrm{ABA}$ & [143] \\
\hline tomato & sitiens & Decreased AM colonization & $\begin{array}{l}\text { ABA plays a role in arbuscular mycorrhizal fungi } \\
\text { symbiosis by regulating the production of SLs }\end{array}$ & $\mathrm{ABA}$ & [144] \\
\hline Physcomitrella & $c c d 8$ & Increased pore germination & $\begin{array}{l}\text { SLs inhibits the germination of Physcomitrella } \\
\text { pore germination }\end{array}$ & & [98] \\
\hline \multirow{2}{*}{ Arabidopsis } & max 2 , ein $2-1$ and etr $1-1$ & Reduced root hair & \multirow{2}{*}{$\begin{array}{l}\text { SL's effect on RH elongation is dependent on both } \\
\text { auxin and ethylene signaling }\end{array}$} & \multirow{2}{*}{ Ethylene and Auxin } & \multirow{2}{*}{ [145] } \\
\hline & tir1, arf7arf19 and aux1 & Increased root hair elongation & & & \\
\hline Arabidopsis & $\max 2$ & \multirow{3}{*}{ Delayed senescence } & \multirow{3}{*}{$\begin{array}{l}\text { SL interacts with ethylene to regulate } \\
\text { leaf senescence }\end{array}$} & \multirow{3}{*}{ Ethylene } & {$[101]$} \\
\hline Pea & dad1/Phccd8 & & & & [75] \\
\hline Rice & dwarf & & & & [146] \\
\hline Pea & rms1 & rms1 are more sensitive to $\mathrm{CK}$ & CKs and SLs contribute to bud outgrowth in pea & CK & [147] \\
\hline Rice & $f c 1, d 10, d 3$ & Increased tillering & $\begin{array}{l}\text { The branching related gene FC1 (FINECULM1) is } \\
\text { insensitive to SLs, but is inhibited by CK }\end{array}$ & CK & {$[148]$} \\
\hline
\end{tabular}


Table 1. Cont.

\begin{tabular}{|c|c|c|c|c|c|}
\hline Species & Mutants & Effects of Mutant & Functions & $\begin{array}{l}\text { Interactions with } \\
\text { Phytohormones }\end{array}$ & References \\
\hline Rice & $d 53$ & Increased CK content & SLs promote CK degradation & CK & [149] \\
\hline Arabidopsis & ahk3, arr1 and arr12 & $\begin{array}{c}\text { Lateral root development insensitive to } \\
\text { GR24 and affected polar } \\
\text { auxin transport }\end{array}$ & $\begin{array}{l}\text { SLs connects with auxins and CKs to regulate } \\
\text { LR development }\end{array}$ & CK and Auxin & [150] \\
\hline Arabidopsis & max 2 and bes 1 & Enhanced rosette branching & MAX2 interacts with BES1 to regulate branching & BR & [151] \\
\hline \multirow{3}{*}{ Arabidopsis } & hy 5 & Shortened hypocotyl & $\begin{array}{l}\text { KARs restore the hypocotyl elongation inhibited } \\
\text { by red light in hy5 }\end{array}$ & & [99] \\
\hline & $g a 1$ & $\begin{array}{l}\text { KAR1 cannot promote the germination } \\
\text { of ga1-3 of GA synthesis defect }\end{array}$ & $\begin{array}{l}\text { KAR1 promotes germination is required for } \\
\text { GA biosynthesis }\end{array}$ & \multirow[t]{2}{*}{ GA } & \multirow[t]{2}{*}{ [83] } \\
\hline & sleepy1 & Delay seed germination & $\begin{array}{l}\text { KAR1 promotes germination is partly dependent } \\
\text { on DELLA }\end{array}$ & & \\
\hline Soybean & Wild type & & $\begin{array}{l}\text { KARs delay seed germination under shaded } \\
\text { conditions by inhibiting GA synthesis and } \\
\text { promoting ABA synthesis }\end{array}$ & GA and $\mathrm{ABA}$ & [100] \\
\hline Arabidopsis & kai2, kai2/d14 & $\begin{array}{l}\text { Decreased root hair density; } \\
\text { Exaggerated skewing and waving }\end{array}$ & $\begin{array}{l}\text { KAI2 signaling pathway regulated root hair and } \\
\text { root development }\end{array}$ & & [124] \\
\hline Lactuca sativa & Wild type & $\begin{array}{l}\text { Smoke-water and } \mathrm{KAR}_{1} \text { promote } \\
\text { seed germination }\end{array}$ & $\begin{array}{l}\text { Application of smoke-water and } \mathrm{KAR}_{1} \text { decrease } \\
\text { ABA content and enhance hydrolase activity to } \\
\text { mobilize stored reserves }\end{array}$ & $\mathrm{ABA}$ & [96] \\
\hline
\end{tabular}




\subsection{SL or KAR Crosstalk with Auxin}

Auxin is a key factor in regulating plant growth and development. Auxin is synthesized mainly at the tops of branches and in young leaves and is transported downward in the main stem by the polar auxin transport stream (PATS) [152]. The TRANSPORT INHIBITOR RESISTANT 1/AUXIN F-BOX (TIR1/AFB) protein recognizes auxin, and together they form a co-receptor complex through E3 ubiquitin ligase with Aux/IAA protein, which acts as a repressor of the transcription of auxin-regulated genes. Aux/IAA interacts with the transcription factor AUXIN RESPONSE FACTOR (ARF) and is ubiquitinated and degraded in an ARF-dependent manner [153]. During auxin signal response, TPL (TOPLESS) interacts with IAA12/BODENLOS (IAA12/BDL) through an ethylene-responsive element binding factor amphiphilic repression (EAR) motif [154]. Interestingly, D53 and SMXL6/7/8 in SL signaling also interact with TPL through the EAR motif $[32,90]$. This result implied that SL and auxin signaling may be integrated by TPL to co-regulate multiple aspects of plant growth and development.

Auxin regulates shoot branching by inducing the expression of CCD7 and CCD8 genes, which are involved in the synthesis of SLs [155]. Transcriptome analysis revealed that SLs inhibit bud growth by negatively regulating auxin transport in rice [156]. SLs regulate root development by inhibiting the transport of auxin from shoots to roots and auxin flux within root tissues, and regulate branching by affecting polar auxin transport (PAT)/canalization in rice [157-159]. When auxin is depleted, SL can inhibit bud outgrowth in pea. The branch number in auxin-response mutants is inhibited by exogenous application of SLs. In addition, the production of auxin-dependent SLs is the main factor inhibiting branches [155]. Additional evidence also supports this view. The inhibition of SLs in main stem branches is dependent on the presence of auxin, while SLs enhance the competitiveness between two branches located on a common stem by inhibiting polar auxin transport [160]. SLs cause the depletion of the auxin exporter PIN1 (PIN-FORMED 1) on the plasma membrane of xylem parenchyma cells in the stem, thus regulating shoot branching [161]. At the same time, it also leads to the accumulation of auxin in the cells of the primary root meristem, which promotes the growth of the taproot, mainly due to an increase in cell length and a decrease in cell diameter [33]. Furthermore, auxin is involved in the regulation of secondary growth and root hair elongation both upstream and downstream of SL, respectively [115,162].

Lower concentrations of SLs promote root hair elongation by inhibiting auxin efflux, but higher concentrations of SLs enhance auxin efflux and inhibit root hair elongation and asymmetric root growth [163]. GR24 does not directly affect the expression of PIN, but the effect of SLs is dependent on the auxin status and seems to modulate the level of auxin. The inhibition of lateral root primordium by SLs is partially mediated via a reduction in the level of auxin, and SLs reduce the levels of auxin in the leaf tissue. For instance, exogenous application of GR24 reduced the content of auxin in the leaf of the SL-deficient max4 mutant [33]. Moreover, SLs affect the formation of lateral roots by affecting the polarity and localization of PIN proteins [159]. Recent studies have shown that PIN1-mediated polar transport of auxin is involved in the regulation of the branching process through the regulation of SLs. A number of auxin exporters, including PIN3, PIN4, and PIN7, play important roles in shoot formation. These transporters regulate a mechanism called connective auxin transport (CAT), which mediates the regulation of branching by SLs in a BRC1-independent manner [139]. Moreover, new evidence shows that sucrose represses the auxin-induced SL pathway to promote bud outgrowth [164], suggesting that sucrose and hormones (auxin and SLs) also play important roles in the regulation of bud outgrowth.

SLs also inhibit adventitious root formation in different plants, such as Arabidopsis, tomato, and pea [120-122], but promote the crown root growth in rice [119]. The effect of auxin on adventitious root formation is opposite to that of SLs, and SLs could partially repress the stimulating effect of auxin on adventitious root formation [120]. SLs strongly interact with auxin signaling to regulate secondary growth, and play a positive role in the pathway downstream of auxin. For example, the positive effect of auxin on cambium was reduced in the max mutants [115]. Altogether, auxin, as a major regulator of the synthesis of SLs, antagonizes the function of SLs by enhancing the transport of auxin [165-167]. 
The interactions between auxin and KAR signaling are still unclear. KARs reduce the level of endogenous auxin by inhibiting the expression of IAA-responsive genes. This promotes seed germination [168].

\subsection{SL or KAR Crosstalk with Gibberellin}

Gibberellic acid (GA) is an important regulator of plant growth and development. Defects in GA synthesis and signaling lead to many defective phenotypes, such as inhibited germination, delayed root growth and flowering, male sterility, dwarfing, reduced rate of seed setting, and increased tiller buds $[169,170]$.

GA-deficient mutants have the same multi-branched phenotype as SL-deficient mutants [171]. Surprisingly, the GA signaling pathway shows the most striking similarities with the SL and KAR signaling pathways. These pathways all contain components that are degraded by the $26 \mathrm{~S}$ proteasome. When GA is recognized by the $\alpha / \beta$ hydrolase receptor GID1 (GIBBERELLIN-INSENSITIVE DWARF 1 ), they form a complex which binds to DELLA proteins to form a stable trimer. Through the E3 ligase $\mathrm{SCF}^{\mathrm{SLY} 1 / \mathrm{GID} 2}$, the DELLA proteins are ubiquitinated and degraded, removing the inhibitory effect of DELLA proteins and allowing plant growth [172-174]. The DELLA proteins in the GA signaling pathway have similar roles as D53-like/SMXL6, 7, and 8 proteins in SL signaling and as SMAX1 in KAR signaling. Previous studies have shown that the SL receptor D14 interacts with the GA signaling repressor SLR1 (SLENDER RICE 1) in an SL-dependent manner in rice [88]. This provides evidence for crosstalk between SLs and GA.

In general, GA participates in the regulation of seed germination by KAR signaling. KARs promote germination of dormant Arabidopsis seeds, and the stimulation of such germination is partly dependent on DELLA proteins. KAR1 can partially restore the inhibited seed germination of the GA-insensitive sleepy1 mutant [83]. ABA may inhibit the effect of KARs on the germination of Arabidopsis seeds by down-regulating the expression of the GA synthesis gene [83]. On the other hand, KARs also inhibit the synthesis of GA by inducing the production of ABA to delay the germination of soybean seeds [100]. Therefore, the upstream and downstream relationships of KARs, ABA, and GA are not completely consistent between different plant seeds, suggesting that they play opposite roles. At the same time, KAR treatment can increase the expression of the $\mathrm{GA}_{3}$ oxidase gene in Arabidopsis seeds [99]. Inhibitors of GA synthesis had an inhibitory effect on seed germination induced by smoke [175]. $\mathrm{KAR}_{1}$ and $\mathrm{GA}_{3}$ synergistically inhibit $\mathrm{ABA}$ activity and release seed dormancy [176].

In the crosstalk between plant hormones, participation in the regulation of the same physiological process does not mean that the plant hormones are mutually dependent on each other to regulate this process. For instance, both SL and GA can affect internode elongation by stimulating cell division, but SL works independently of the GA signal in this process [177]. In addition, the roles of SL and GA in branch regulation are independent in pea [178]. $\mathrm{GA}_{3}$ could significantly increase seed germination of kai2 and max 2 mutants, indicating that KAI2 and MAX2 may not be involved in the stimulation of GA on seed germination [63].

\subsection{SL or KAR Crosstalk with Abscisic Acid}

SLs and ABA are both derived from the carotenoid pathway, beginning with the transformation of 9-cis/all-trans-carotene into the precursor all-trans-violaxanthin [54]. The similarity of the synthetic pathways provides a sufficient and favorable basis for the interaction between SL and ABA functions. First of all, ABA and SL affect each other's synthesis. For instance, in the ABA-deficient mutants up14 (maize), notabilis and sitiens (tomato), the transcriptional levels of the SL synthesis genes CCD7 and CCD8 are reduced, which leads to decreased content of SLs in root secretion [141]. Further, SL synthesis is regulated by ABA in Arabidopsis [41]. KARs negatively regulate seed germination by inhibiting GA synthesis and promoting ABA synthesis in soybean [100]. It was also reported that the max2 mutant has lower ABA sensitivity. In addition, the MAX2 gene was detected at high expression levels in ABA-treated seedlings, implying that MAX2, as an important component of SL signaling, 
also participates in the ABA signaling pathway $[48,142]$. During study of symbiosis, it was found that AM colonization was decreased in the ABA-deficient mutant sitiens, suggesting that ABA plays a role in arbuscular mycorrhizal fungi symbiosis by regulating the production of SLs [141,144]. A recent study indicated that ABA is also involved in SL-mediated dormancy of axillary buds in rice, which represents a new insight into the mechanism by which SL inhibits outgrowth of axillary buds [179]. Moreover, CYP707As, involved in abscisic acid catabolism, are effectors newly discovered to be involved in SL and KAR responses in Arabidopsis and parasitic plants [180]. However, how CYP707As link ABA and SL/KAR signaling remains unclear.

\subsection{SL or KAR Crosstalk with Ethylene}

Ethylene, a gaseous plant hormone, is involved in regulating seed germination, hypocotyl elongation, root and root hair elongation, inhibition of lateral root development, and leaf senescence [98, 145]. Ethylene is produced during the germination of most seeds, and ethylene promotes seed germination in a dose-dependent manner [181,182]. SLs promote the production of ethylene [183]. These results imply that ethylene is involved in the regulation of seed germination by SLs, and that ethylene biosynthesis is essential for SL-mediated promotion of seed germination [184]. AVG, an inhibitor of ethylene biosynthesis, also inhibits seed germination induced by the SL analogue GR24, but this effect could be overcome by ACC (a reaction product of AVG inhibition) [182]. In addition, both SLs and ethylene are positive regulators that depend on a common regulatory pathway, at least in root hair elongation. In the ethylene signaling-deficient ein 2 and etr 1 mutants, the root hair elongation response to SLs is reduced. These results indicated that the synthesis of ethylene was necessary for the promotion of root hair elongation by SLs, while it is also possible that auxin signaling could be integrated with SL and ethylene signaling to regulate the elongation of root hairs [145].

The formation of adventitious roots can be regulated by both SLs and ethylene. Previous research suggested that SLs and ethylene played independent roles in adventitious root formation, but that the ethylene precursor ACC and SLs played antagonistic roles in the first third of the hypocotyl. ACC promoted adventitious root formation, while ACC and SLs inhibited adventitious root formation in the lower part of the hypocotyl [185].

SL-deficient and SL-insensitive mutants, including max2 in Arabidopsis, dad1 in pea and dwarf mutants in rice, exhibited delayed senescence. Moreover, the delayed senescence of leaves caused by the absence of SLs was inhibited by application of SLs $[75,101,146]$. Ethylene is also involved in the regulation of leaf senescence. Ethylene treatment significantly induced the expression of the SL synthesis genes MAX3 and MAX4, indicating that SLs can be synthesized in senescent leaves. At the same time, exogenous SL application in the presence of ethylene enhanced the promotion of ethylene on leaf senescence [34].

\subsection{SL or KAR Crosstalk with Cytokinin}

Cytokinins (CKs) are plant hormones that can either cooperate with or antagonize the action of SLs in regulating plant growth and development. For example, SLs inhibit the elongation of rice mesocotyl cells, while CKs promote it [186]. The antagonism between CKs and SLs was also demonstrated in the regulation of bud outgrowth in pea [147]. In rice, the branching related gene FC1 (FINECULM1) is insensitive to SLs, but is inhibited by CKs [148]. The expression of BRC1, a homolog of FC1 in pea, is promoted by SLs and inhibited by CKs $[112,147]$. Recent studies have shown that SL promotes the degradation of CKs through activating the expression of CKX9 (CYTOKININ OXIDASE 9) in rice, which encodes an oxidase that catalyzes the degradation of CK [149]. In rice $d 53$ mutants, the CK content in the stem base is significantly increased. The expression of the CK catabolic enzyme OsCKX9 is induced by GR24 in wild type but not in $d 53$ mutant. Moreover, OsCKX9 responds to SLs and plays a role in the SL signaling pathway [149]. In these ways, SLs and CKs are involved in regulating shoot architecture in rice. 
The SL-response mutant max2 shows decreased sensitivity to the synthetic CK 6-Benzylaminopurine (BAP) [187]. SLs inhibit the formation of lateral roots in a MAX2-dependent manner. The CK signaling components AHK3 (HISTIDINE KINASE 3), ARR1 (RESPONSE REGULATOR 1), and ARR12 (RESPONSE REGULATOR 12) are involved in the effects of GR24 on lateral root development. SLs also influence the formation of lateral roots by affecting the polarity of auxin $[150,159]$. Therefore, the development of lateral roots is accompanied by crosstalk among SLs, auxin, and CKs. Interestingly, the inhibition of adventitious roots by SLs is independent of CK [120]. CK is also involved in the regulation of seed germination, and the SL analogue GR24 promotes increases in the content of CK in Striga seeds, indicating that SLs are an upstream signal of CK during the regulation of seed germination [97].

The TMB can inhibit the germination of lettuce seeds. On the one hand, it increases ABA content through a photosensitive pigment system, on the other hand, it inhibits cytokinin homeostasis under dark conditions [100]. Another evidence that KAR is involved in regulating CK is that $K_{A} R_{1}$ and $S W$ are able to raise the levels of primary endogenous cytokinins in Eucomis autumnalis and Spinacia oleracea $\mathrm{L}$ plants. For example, SW and $\mathrm{KAR}_{1}$ increase significantly the levels of ciszeatin, dihydrozeatin, and isopentenyladenine of CKs and then yield a greater number of leaves in spinach plants [188]. Meanwhile, SW and $\mathrm{KAR}_{1}$ treatments also accumulate higher concentrations of isoprenoid-type CKs in the aerial organs of Eucomis autumnalis [189]. These data indicate that the crosstalk between KAR and CK also plays an important role in plant growth and development.

\subsection{SL or KAR Crosstalk with Other Hormones}

SLs can also interact with other plant hormones to regulate plant growth and development. It was found that MAX2 interacts with BES1 (bri1-EMS-suppressor 1), a positive regulator in the brassinosteroid signaling pathway, to accelerate the degradation of BES1 in the presence of SLs [151]. Recent study showed that the contents of free phenolic acids and salicylic acids were increased significantly in spinach plants treated with $\mathrm{SW}$ and $\mathrm{KAR}_{1}$, implying that there is a crosstalk possibility between KAR and salicylic acid [188].

\section{SLs and KARs During Abiotic Stress: Responses and Adaptation}

\subsection{Dynamic Regulation of SLs Under Abiotic Stresses}

In recent years, substantial evidence has demonstrated that SLs and KARs are involved in the regulation of the plant responses to abiotic stress $[8,37,38,41-43,46,63,143,190,191]$ (Table 1). SL levels are finely modulated under various types of abiotic stress. Recent studies have shown that SL biosynthesis is repressed in the roots of tomato plants under drought stress conditions. Moreover, a drop in the biosynthesis of SL in roots during drought may act as a systemic signal affecting SL synthesis in aboveground organs $[38,143]$. Interestingly, drought increases the abundance of transcripts of the SL-biosynthetic genes SICCD7 and SlCCD8 in tomato shoots and the D27 and MAX1 homologs Os01g0700900, Os01g0701400, Os02g0221900, and Os06g0565100 in rice shoots [38,40]. Additionally, the SL-biosynthetic genes MAX3 and MAX4 are significantly induced by dehydration and salinity in leaves of Arabidopsis [41]. Essentially, these findings suggest that an efficient activation of SL biosynthesis is triggered in response to osmotic stress, leading to the activation of SL signaling, which positively regulates the tolerance of these adverse conditions.

\subsection{SL- and KAR-Mediated Plant Adaptation to Abiotic Stresses}

Numerous loss-of-function and exogenous SL treatment studies have revealed that SLs contribute to the responses to drought and salinity in Arabidopsis, rice, and rapeseed [40-42]. In Arabidopsis, hypersensitivity to drought and salt stress was observed in mutants of both the SL-biosynthetic genes $M A X 3$ and MAX4 and the SL-signaling gene MAX2 [41]. Additionally, transcriptome analysis of max 2 leaves revealed that genes related to drought and ABA responses are downregulated. On 
the other hand, photosynthetic genes, which are generally repressed under dehydration in an ABA-independent manner, are upregulated in max 2 compared to wild type (WT) leaves under normal and drought conditions [41]. This implies that MAX2 regulates the drought stress response in both an ABA-dependent and ABA-independent manner.

Spraying plants with SL confirmed the role of SL as a positive regulator in stress responses. In grapevine, foliar application of GR24 could alleviate drought stress by regulation of stomatal closure and photosynthesis and activation of antioxidant defense [50]. SL-deficient Lotus japonicas Ljccd7- and tomato SIccd7-silenced transgenic plants also exhibit sensitivity to osmotic stress [38,143]. Interestingly, research on Arabidopsis and tomato indicates that SLs contribute to ABA-mediated stomatal closure under drought stress [38,41]. Recently, SLs were reported to contribute to the triggering of stomatal closure by stimulating the production of $\mathrm{H}_{2} \mathrm{O}_{2}$ and NO. This implies that SL signaling is linked to $\mathrm{H}_{2} \mathrm{O}_{2}$ and NO signaling in adverse conditions [37]. MAX2 functions in two pathways: D14-mediated SL signaling and KAI2-mediated KAR/KL signaling. The drought sensitivity of max 2 may be attributed to defects in the signaling pathways of SL, KAR/KL, or both. A recent study has shown that the KAR/KL receptor KAI2 positively regulates tolerance to drought stress by enhancing cuticle formation, stomatal closure, cell membrane integrity and anthocyanin biosynthesis in Arabidopsis [8]. These findings suggest that the KAR/KL-mediated signaling pathway also contributes to the improvement of drought tolerance in plants. Additionally, Li et al. (2017) reported that $d 14$ mutant plants are more sensitive to drought stress compared to wild type, indicating that the SL receptor D14 is also involved in drought responses [8]. Interestingly, d14kai2 double mutant plants are more sensitive to drought stress than the d14 and kai2 single mutants [8], suggesting that the D14-mediated SL pathway and the KAI2-mediated KAR pathway act together to enhance tolerance to drought stress in Arabidopsis.

The max2 and kai2 mutants exhibit decreased cuticle thickness and enhanced cuticular water permeability, implying that SL and/or KAR signaling pathways are involved in regulating cuticle thickness $[8,48]$. In contrast, the $d 14$ mutant does not exhibit cuticle defects, unlike the kai2 mutant and the d14kai2 double mutant [8]. This implies that a D14- or KAI2-dependent signaling component may exist as a distinct mechanism in adaptation to drought in Arabidopsis. Recently, Wang et al. (2018) reported that the germination of kai2 seeds is more sensitive to osmotic stress, salinity, and high temperatures [63]. Interestingly, KAR-induced KAI2 signaling promotes germination under favorable conditions and inhibits germination under unfavorable conditions in Arabidopsis seeds. This suggests that KAI2-mediated signaling may play an important role in responses to abiotic stress by maintaining viability while inhibiting germination under unfavorable conditions [63].

Nitrogen $(\mathrm{N})$ and phosphate $(\mathrm{P})$ are key nutrients required for plant growth. A deficiency in these nutrients critically affects the sustainable production of crops [192]. Several studies have reported that SLs are involved in the regulation of root development under P- or N-deficient conditions. In rice, the $d 10$ and $d 27$ mutants in SL-synthesis and the $d 3$ mutant in SL-signaling decreased seminal root density and increased lateral root density during P or N starvation compared to wild type. In addition, the exogenous application of GR24 restored the reduced response to low-P or low-N conditions in the $d 10$ and $d 27$ mutants, suggesting that SLs promote seminal root development and negatively regulate lateral root development under nutrient stress [157,193]. In Arabidopsis, SL-deficient max4 and SL-response max 2 mutants have shorter root hair lengths under low-P conditions compared with wild type. This defective phenotype can also be restored with GR24 in the max4 mutant [47]. Collectively, SLs may trigger the fine-tuning of root architectures via the MAX2 component of SL signaling under unfavorable nutritional conditions to promote plant adaptation to adverse environments.

SLs have recently been reported to positively regulate chilling tolerance in pea plants and Arabidopsis [43]. In pea, biomass accumulation was decreased in the SL-signaling mutant ramosus3 (rms3) and the SL-synthesis mutant $r m s 5$ after chilling in the dark. Similar results were also observed for the SL-synthesis max4 mutant in Arabidopsis [43]. Also under dark chilling, photosynthetic carbon assimilation was inhibited in rms mutants in pea and in $\max 3$, max4, and max 2 mutants in Arabidopsis [43]. These finding suggest that SLs play a role in the dark chilling tolerance of 
photosynthesis in pea plants and Arabidopsis. In addition, a significant reduction in leaf area has been observed following dark chilling treatment in the presence of GR24 [43], implying that SL signaling may help plants adapt to a low temperature environment by regulating the growth of leaves under chilling stress. However, this needs to be clarified in the future studies.

Several flavonoid biosynthesis-related genes are significantly repressed by dehydration stress treatments in both max2 and kai2 mutants compared with those in wild type. This implies that SL and/or KAR can positively regulate flavonoid biosynthesis under drought stress [8,41]. Indeed, a lower level of anthocyanin has been observed in kai2 mutant plants compared with wild type under water-deficit conditions [8]. In addition, the abundance of several flavonol biosynthesis-related enzymes are significantly reduced in the max2 mutant, while GR24 is able to induce flavonol accumulation in a MAX2-dependent manner [194]. It is well known that flavonoids/anthocyanins protect plant tissue from various environmental stresses [195-197]. These results suggest that the SL and KAR signaling pathways are able to stimulate anthocyanin accumulation under adverse conditions, which may contribute to drought tolerance in plants (Figure 5).

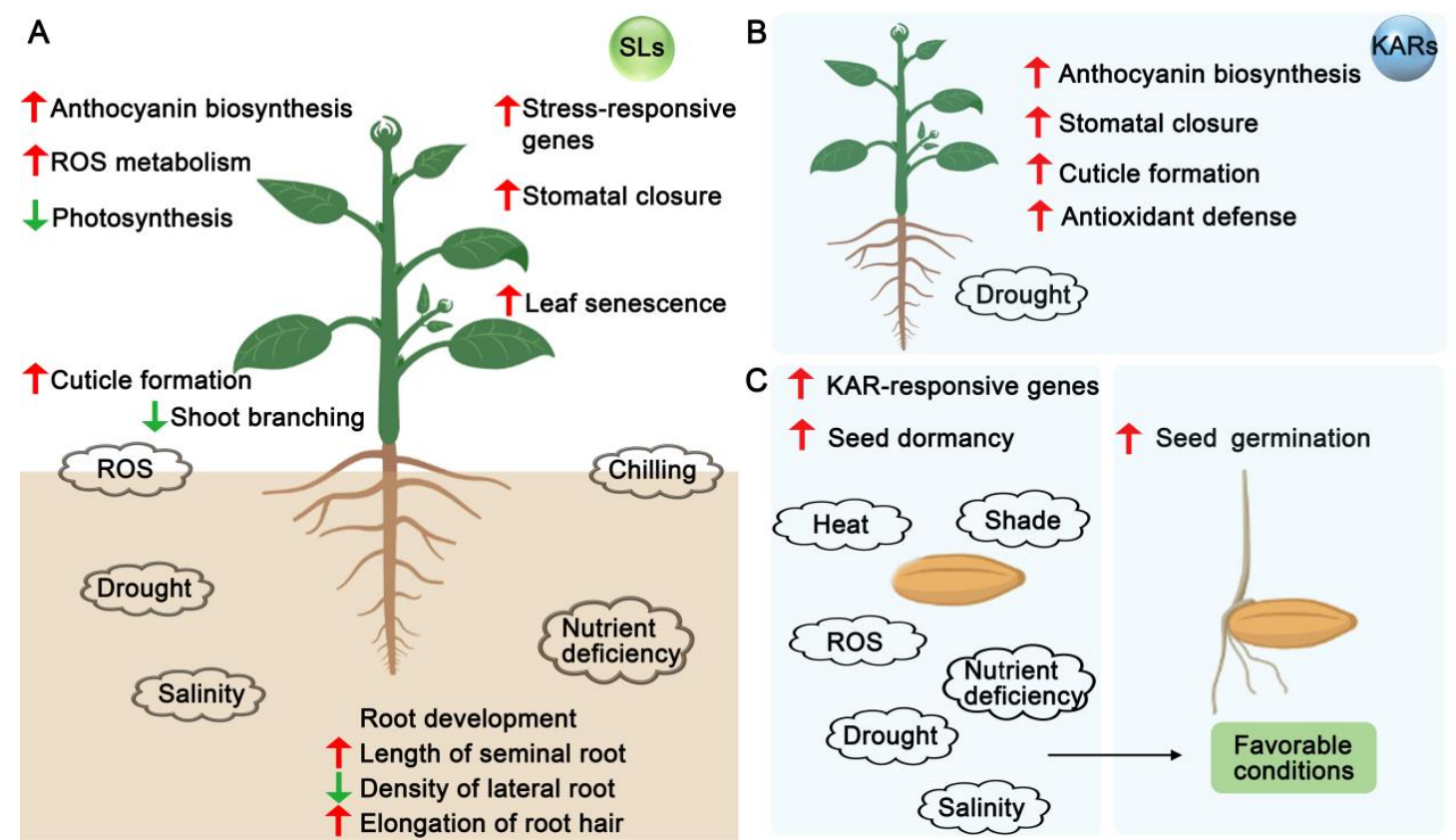

Figure 5. Model for the involvement of SLs and KARs in various abiotic stress responses. (A) Increasing evidences suggest that SLs are involved in plant adaptation to abiotic stresses (e.g., drought, salinity, nutrient deficiency, chilling, and oxidative stress). SLs can fine-tune root development by increasing the length of seminal roots and root hairs and decreasing the density of lateral roots. Aboveground, elevated levels of SLs in shoots may positively regulate stomatal closure, cuticle formation, and stress-responsive genes to reduce water loss. SLs may also be involved in accelerating leaf senescence by activating ethylene-mediated senescence signaling, which may further activate the process of nutrient relocation under abiotic stresses. In addition, SLs may also inhibit shoot branching and photosynthesis to optimize plant adaptation to stress. SLs are also involved in regulating anthocyanin biosynthesis to alleviate oxidative stress induced by various abiotic stresses. (B) KARs contribute to the protection against abiotic stress during seed germination and promote drought resistance in Arabidopsis. (C) KARs-KAI2 signaling can maintain seed dormancy and inhibit germination under abiotic stress and can stimulate seed germination under favorable conditions. Upward red arrows indicate a positive response, and downward green arrows indicate a negative response. SLs, strigolactones; KARs, karrikins; ROS, reactive oxygen species. 


\section{SLs and KARs Crosstalk with Other Phytohormones Under Abiotic Stresses}

Several studies have provided evidence for the interaction of SL or KAR signaling with the signaling of other hormones during responses to biotic and abiotic stress (Table 2) [40,41,52,137,165,167,191,198-201]. Both SLs and ABA biosynthetically originate from carotenoids [202]. Reduced SL levels in ABA-biosynthesis mutants have been observed in tomato plants [141,203], while SL-deficient tomato mutants exhibited a reduction in the levels of ABA [204]. This suggests that ABA and SL interact with each other during biosynthesis. These results agree with the observed reduction of ABA levels under low-P and osmotic stress conditions for SL-deficient CCD7RNAi lotus plants [143], implying that SL deficiency reduces ABA levels. Moreover, it has been reported that SL signaling-mediated adaptation to drought stress is associated with ABA-mediated stomatal closure [38,41]. In addition, exogenous GR24 pretreatment may increase stomata sensitivity to ABA in tomato plants [38]. In Arabidopsis, drought-susceptible max2 plants exhibited impaired ABA-mediated stomatal closure [41,48], yet no differences in ABA contents have been observed between the wild type and max2 following drought treatment [48]. Additional evidence has demonstrated that SL positively regulates the stress and ABA signaling pathways by regulating the expression of many stress and/or ABA-responsive genes, which are involved in abiotic stress response [41]. These findings suggest that SL-promoted drought tolerance may be a partially ABA-dependent pathway in plants. However, in rice, the SL biosynthetic dwarf10 (d10) and $d 17$ mutants and the SL perception $d 3$ mutant exhibit an increased ABA concentration under normal and drought conditions and enhanced drought tolerance when compared with wild type [40]. In contrast, the mutation of D27, which encodes the initial enzyme in SL biosynthesis and involves the conversion of all-trans- $\beta$-carotene to 9-cis- $\beta$-carotene, decreased the ABA levels and drought tolerance [40], while overexpression of OsD27 increased the levels of ABA. These results demonstrate that SL signaling is linked to the ABA pathways through D27, which plays an important role in determining the ABA and SL content in rice. These contradictory observations, of ABA levels in rice SL mutants on the one hand and Arabidopsis, tomato, and lotus on the other hand, may be due to differences in monocots and dicots. The different mechanisms could be revealed by performing comparative genome-wide expression profiling studies among these plant species.

A recent study has reported that kai2 mutant plants exhibit a decreased sensitivity to ABA, suggesting that KAI2 positively regulates the ABA response [8]. In addition, kai2 mutants exhibit increased $\mathrm{ABA}$ concentrations compared to wild type under both well-watered and dehydration conditions. This may due to the downregulated ABA catabolic gene CYP707A3 and ABA transport-related genes $A B C G 40$ and $A B C G 22$ in kai2 when compared with wild type [8]. A recent study demonstrated that the CYP707A protein, which is involved in ABA catabolism, may act as an effector of the KAR and SL signaling pathways in Arabidopsis and parasitic plants [180]. These findings provide evidence for the involvement of the crosstalk between ABA- and KAI2-dependent signaling pathways in plant adaptation to drought. Interestingly, ABA-mediated stomatal closure and the reduced sensitivity to ABA may be common strategies in SL and KAI signaling for adaptation to drought $[8,41,48]$. The mechanisms of SL and/or KAR signaling in regulating ABA-mediated stomatal movement need to be further clarified in the future. 
Table 2. Mutations of strigolactone (SL) and karrikin (KAR)-related genes that alter the effects in various plants species under different abiotic stresses.

\begin{tabular}{|c|c|c|c|c|c|}
\hline Genotypes & Types of Stresses & Mutants or Transgenes & Effects & $\begin{array}{c}\text { Interactions with } \\
\text { Phytohormones }\end{array}$ & References \\
\hline Arabidopsis & $\begin{array}{l}\text { Drought stress and } \\
\text { salinity }\end{array}$ & $\begin{array}{c}\max 2-3, \max 2-4, \max 3-11 \\
\max 3-12, \max 4-7, \text { and } \max 4-8\end{array}$ & $\begin{array}{l}\text { SLs positively regulate plant responses to } \\
\text { drought and salt stress }\end{array}$ & $\mathrm{ABA}$ and $\mathrm{CK}$ & [41] \\
\hline Arabidopsis & Drought stress & $\begin{array}{l}\max 2-1, \max 2-2, \max 1, \max 3 \\
\text { and } \max 4\end{array}$ & $\begin{array}{l}\text { MAX2 play an important role in plant } \\
\text { responses to abiotic stress }\end{array}$ & ABA & [48] \\
\hline Lotus japonicus & $\begin{array}{c}\text { Phosphate starvation and } \\
\text { osmotic stress }\end{array}$ & LjCCD7-silenced line ( $L j c c d 7)$ & $\begin{array}{l}\text { SLs contribute to drought resistance in } \\
\text { Lotus japonicus }\end{array}$ & ABA & [143] \\
\hline Arabidopsis & $\begin{array}{l}\text { Wounding, heat, UV-B, } \\
\text { salinity }\end{array}$ & Wild type & Abiotic stresses responses & $\begin{array}{l}\text { ABA, CK, IAA, BR, ET, } \\
\text { GA, and MeJA }\end{array}$ & [205] \\
\hline Tomato & Drought & SlCCD7-silenced line ( $L j c c d 7)$ & $\begin{array}{l}\text { Low levels of SLs in roots act as components } \\
\text { of the systemic signal of drought stress }\end{array}$ & $\mathrm{ABA}$ & [38] \\
\hline Tomato & Drought and AMF & Wild type & $\begin{array}{l}\text { AMF induces SL biosynthesis under drought } \\
\text { and improves drought tolerance }\end{array}$ & $\mathrm{ABA}$ & [46] \\
\hline Festuca arundinacea & $\begin{array}{l}\text { PEG-induced drought } \\
\text { stress }\end{array}$ & Wild type & $\begin{array}{l}\text { Drought-inhibition of tiller development and } \\
\text { growth in grass species are associated with } \\
\text { SL accumulation and signaling }\end{array}$ & & [206] \\
\hline Rapeseed & salinity & Wild type & $\begin{array}{l}\text { Salinity depresses the shoots and roots } \\
\text { growth, whereas GR24 improves the growth } \\
\text { under salt stress }\end{array}$ & & [42] \\
\hline Sesbania cannabina & Salinity and AMF & Wild type & $\begin{array}{l}\text { SLs enhance salt stress tolerance, and the } \\
\mathrm{H}_{2} \mathrm{O}_{2} \text {-induced SL accumulation was } \\
\text { accompanied by increased salt tolerance }\end{array}$ & & [207] \\
\hline Rice & Drought stress & $\begin{array}{c}d 10, d 17, d 27 \text {, and } d 3, \\
D 27 \text {-overexpressing plants }\end{array}$ & $\begin{array}{l}\text { SL biosynthesis/perception interferes with } \\
\text { ABA formation, and D27 plays a crucial role } \\
\text { in determining ABA and SL content }\end{array}$ & $\mathrm{ABA}$ & [40] \\
\hline Sesbania cannabina & Salinity and AMF & Wild type & $\begin{array}{l}\mathrm{ABA} \text { is regulating the induction of salt } \\
\text { tolerance by SL in AM seedlings }\end{array}$ & $\mathrm{ABA}$ & [39] \\
\hline Arabidopsis & Dark & $\begin{array}{l}\max 1-1, \max 3-9, \max 4-11, \\
\text { Atd14-1, and } \max 2-4\end{array}$ & $\begin{array}{l}\text { ET synthesis and consequent SL synthesis } \\
\text { are required for the efficient progression of } \\
\text { dark-induced leaf senescence. }\end{array}$ & ET & [34] \\
\hline Arabidopsis & Phosphate deficiency & $\max 2-1$ and $\max 4-1$ & SLs regulate the response of plants to low $\mathrm{Pi}$ & Auxin & [34] \\
\hline
\end{tabular}


Table 2. Cont.

\begin{tabular}{|c|c|c|c|c|c|}
\hline Genotypes & Types of Stresses & Mutants or Transgenes & Effects & $\begin{array}{c}\text { Interactions with } \\
\text { Phytohormones }\end{array}$ & References \\
\hline Rice & $\begin{array}{l}\text { Phosphate- and } \\
\text { nitrate-deficiency }\end{array}$ & $d 3, d 10$, and $d 27$ & $\begin{array}{l}\text { SLs affect root growth in rice under } \\
\text { phosphate and nitrate limitation by } \\
\text { decreasing auxin transport from shoots } \\
\text { to roots }\end{array}$ & Auxin & [157] \\
\hline Rice & $\begin{array}{l}\text { Phosphate- and } \\
\text { nitrate-deficiency }\end{array}$ & $d 3, d 10$, and $d 53$ & $\begin{array}{l}\text { SLs involve in NO-activated elongation of } \\
\text { seminal root under nitrogen and phosphate } \\
\text { deficiency conditions. }\end{array}$ & & [193] \\
\hline $\begin{array}{l}\text { Arabidopsis } \\
\text { and pea }\end{array}$ & Dark chilling & $\begin{array}{c}\text { max2-1, max3-9, and max4-1 in } \\
\text { Arabidopsis; rms5-3, rms4-1, and } \\
\text { rms3-1 in pea }\end{array}$ & $\begin{array}{l}\text { SLs positively regulate chilling tolerance in } \\
\text { pea and in Arabidopsis }\end{array}$ & & [44] \\
\hline Arabidopsis & Drought stress & kai2-2, kai2-4, and d14-2 & $\begin{array}{c}\text { The KAR receptor KAI2 promotes } \\
\text { drought resistance }\end{array}$ & $\mathrm{ABA}$ & {$[8]$} \\
\hline Arabidopsis & $\begin{array}{c}\text { Osmotic stress and } \\
\text { salinity }\end{array}$ & kai2-2, d14-1, $\max 2-1$ and $\max 2-7$ & $\begin{array}{l}\text { Karrikin-KAI2 signaling system can protect } \\
\text { against abiotic stress }\end{array}$ & GA and ABA & [63] \\
\hline
\end{tabular}


In Arabidopsis, transcriptome analysis has revealed that the four CK catabolism-related genes cytokinin oxidase 1 (CKX1), CKX2, CKX3, and CKX5 were downregulated in the max2 mutant prior to and during dehydration [41]. Previous studies have reported that the overexpression of CKX1, CKX2, CKX3, and CKX4 increased responses to ABA and improved the tolerance to drought and salt in Arabidopsis and tobacco $[208,209]$. The CK signaling pathway has been shown to negatively regulate tolerance to drought and salt stress by antagonizing ABA signaling [13,209]. These findings suggest that SL signaling and/or KAR signaling may negatively regulate CKX-mediated CK levels during dehydration, which subsequently contribute to the modulation of stress tolerance by influencing the ABA response. Although CKs and SLs have been reported to antagonistically regulate bud activation and shoot branching $[147,166]$ and to synergistically regulate lateral root development [150], direct evidence of the interaction between SL signaling and CK signaling under abiotic stress is lacking [210]. The hypothesis that SL and/or KAR signaling positively regulate abiotic stress tolerance in plants by reducing CK contents and/or inhibiting CK signaling remains to be further demonstrated. In addition, studies on the CK/SL biosynthesis mutants and CK/SL signaling mutants under drought conditions will contribute to the revealing of the potential crosstalk between the SL and CK signaling pathways in plant adaptation to drought stress.

A recent study has provided evidence that GA and the synthetic SL rac-GR24 result in predominantly additive transcriptional changes of a largely overlapping set of genes [201]. A previous study reported that SLs alleviate seed thermoinhibition by modulating the ABA/GA ratio via decreasing ABA levels and increasing GA levels in Arabidopsis, suggesting that SL may act upstream of ABA and GA to regulate seed thermoinhibition [97]. Furthermore, the application of exogenous $\mathrm{GA}_{3}$ stimulates seed germination of wild type, the SL-related $d 14$ and max 2 mutants, and the KAR-related kai2 mutant in both the absence and presence of $\mathrm{NaCl}$ in Arabidopsis [63]. This finding implies that the promotion of seed germination by $\mathrm{GA}_{3}$ is independent of the D14-MAX2 or KAI2-MAX2 signaling pathways in Arabidopsis. Additionally, GA negatively affects SL biosynthesis by regulating the expression of SL biosynthesis genes in rice [140]. Moreover, application of exogenous GA reduced the infection of rice by the parasitic plant Striga [140]. These results suggest that crosstalk between the GA and SL signaling pathways may be an advantage for the management of root parasitic weeds.

In Arabidopsis, the SL-biosynthesis mutants $\max 1, \max 3$, and $\max 4$ and the SL-response mutants $d 14$ and max 2 exhibited a delay in leaf senescence during dark and ethylene treatments. However, this was not the case for the KAR-response mutant kai2 [34]. Moreover, MAX3 and MAX4, which are important SL biosynthesis genes, were strongly induced during dark and ethylene treatments [34]. In addition, leaf senescence was triggered by the application of GR24 only in the presence of ethylene and not by GR24 alone. These findings suggest that SLs are involved in the acceleration of leaf senescence by activating ethylene-mediated senescence signaling [34]. It is well known that leaf senescence is an active process of nutrient relocation, which is beneficial for recycling nutrient materials from dispensable leaves [210]. Although the underlying mechanism of the interaction between SL and ethylene under abiotic stress conditions is unclear, we hypothesize that the crosstalk between ethylene and SL may have the ability to accurately regulate leaf senescence under adverse environmental conditions. Future studies will be required to fully understand crosstalk between ethylene and SL signaling in processes such as leaf senescence and adaptation to abiotic stress, and how SL signaling components activate ethylene signaling under normal and adverse conditions.

Several studies have revealed that the crosstalk between auxin and SL signaling is the predominant contributor to the regulation of root development under nutrient shortages $[145,157]$. Experimental data in rice suggest that SLs can fine-tune root architectures by modulating the transport of auxin from shoots to roots under $\mathrm{N}$ and $\mathrm{P}$ limitation, which in turn increases the seminal root length and decreases lateral root density. In addition, the additive effect on root hair elongation has been reported for SLs and auxin [145]. Furthermore, ethylene was also involved in the SL-auxin crosstalk during the elongation of root hairs. Here, ethylene may be epistatic to SLs, acting as a crosstalk junction between them [145]. Taken together, SLs and KARs play essential roles in plant abiotic responses, and they 
interact with other hormones, including ABA, CK, GA, ethylene, and auxin, to cooperatively regulate the adaptation of plants to abiotic stress.

\section{Conclusions and Perspectives}

Significant progress has been made towards an understanding of how the SL and KAR signaling pathways influence plant developmental and environmental responses. The majority of recent studies have focused on the biosynthesis and perception of SLs and KARs. However, studies on SLs and KARs in plant adaptation to environmental stresses are still at the basic stage. The involvement of SLs in regulating the responses to drought, salinity, and nutrient deficiency stress as well as chilling tolerance has been demonstrated $[38,40-43,47,48,157,193]$. KARs are also involved in the regulation of drought tolerance and provide seeds with abiotic stress tolerance in Arabidopsis $[8,63]$.

However, the downstream targets of SL and/or KAR signaling pathways are not fully understood under normal or adverse environmental conditions, and the signal transduction pathway of KAR is still unclear. Moreover, there are still many outstanding questions that remain to be studied in depth. How can SLs and KARs be differentiated and regulate different signaling pathways in a MAX2-dependent manner in plant growth and development processes? What is the basis for the degradation of SMXL family proteins by ubiquitination and the $26 \mathrm{~S}$ proteasome in different signaling pathways? What are the roles of SMXL1 and SMXL6, 7, 8, and how quickly do they perceive the signals of SL and KAR? Do SMXL family members directly regulate downstream transcription factors or indirectly through other proteins? All these questions indicate that there is still work to do to identify components of the SL and/or KAR signaling pathways and to investigate the functions of these members (e.g., SL-receptor AtD14 and the KAR-receptor KAI2). It is critical to determine the core components (e.g., MAX2, SMAX1/2, and D53/SMXLs), the yet-unknown components, and the shared components. In particular, SMAX1-LIKE/D53 family members act as transcriptional repressors of SL and KAR signaling to regulate shoot development $[32,90]$. Studies on the involvement of these components in plant abiotic stress, their partners and downstream transcriptional targets will further help elucidate the common or specific mechanisms of SL and KAR signaling under environmental stress. Although SLs and KARs are both butenolide molecules, plants may distinctly perceive the diverse endogenous SL and KAR/KL molecules in order to trigger optimal developmental and environmental responses. However, the endogenous KAI2-ligand remains undetected, while determining it will provide important clues for understanding KAR signaling. In addition, the production of natural SLs is limited, while their natural structures are complex and diverse. Therefore, simple and efficient detection and synthesis technologies will promote SL biological research and application, particularly in agricultural production.

SL and KAR signaling pathways may be positively involved in the regulation of flavonoid/anthocyanin syntheses in an MAX2-dependent manner under drought stress [7,40,193]. This suggests that SL and KAR signaling pathways may link the signaling pathways of reactive oxygen species (ROS) in plant responses to environmental stresses. ROS signaling has been shown to be an integral part of the abiotic stress-response mechanism, so, it remains to be determined if there is crosstalk between SL and ROS signaling under adverse environmental conditions. This crosstalk might be one approach to improving plant tolerance of abiotic stress.

SLs and/or KARs are able to link other hormone pathways and may form a regulatory network for various aspects of plant development and adaptation to abiotic stress. However, any crosstalk between SLs/KARs and salicylic acid (SA) and SLs/KARs and jasmonate (JA) has not been established due to limited experimental data. The interaction between SLs/KARs and other hormones under abiotic stress must be further explored using physiological, biochemical, genetic, and molecular biological methods. This work will clarify this complex regulatory network. Furthermore, comparative analyses using transcriptomics, proteomics, metabolomics, and functional genomics promise to add insights into the SL/KAR regulatory network. The use of CRISPR-Cas9-mediated genetic manipulation of SL and KAR signaling pathways also should provide new revelations about the molecular mechanisms by 
which SLs and KARs influence plant development and adaptation to stress and may provide valuable resources for crop breeding.

Author Contributions: C.W. and T.Y. conceived of and designed the main content. T.Y. and Y.L. designed and produced the figures, and T.Y. summarized a table. C.W., T.Y. and Y.L. wrote the article.

Funding: This work was funded by the National Natural Science Foundation of China (NSFC) (Grant Nos. 31770199, 31670254 and 31700215), the China Postdoctoral Science Foundation (Grant No. 2016M600824), and the Foundation of the Key Laboratory of Cell Activities and Stress Adaptations, Ministry of Education of China (lzujbky-2017-kb05 and lzujbky-2018-kb05).

Conflicts of Interest: The authors declare no conflict of interest.

\section{Abbreviations}

$\begin{array}{ll}\text { SL } & \text { Strigolactone } \\ \text { KAR } & \text { Karrikin } \\ \text { ABA } & \text { Abscisic acid } \\ \text { CK } & \text { Cytokinin } \\ \text { GA } & \text { Gibberellic acid } \\ \text { ET } & \text { Ethylene } \\ \text { SA } & \text { Salicylic acid } \\ \text { JA } & \text { Jasmonate } \\ \text { BR } & \text { Brassinosteroid } \\ \text { D10 } & \text { DWARF10 } \\ \text { D14 } & \text { DWARF14 } \\ \text { D27 } & \text { DWARF27 } \\ \text { D53 } & \text { DWARF53 } \\ \text { KAI2 } & \text { KARRIKIN INSENSITIVE 2 } \\ \text { MAX2 } & \text { MORE AXILLARY GROWTH 2 } \\ \text { SMAX1 } & \text { SUPPRESSOR OF MAX2 1 } \\ \text { SMXL } & \text { SMAX1-LIKE } \\ \text { LBO } & \text { LATERAL BRANCHING OXIDOREDUCTASE } \\ \text { CCD } & \text { CAROTENOID CLEAVAGE DIOXYGENASE } \\ \text { RMS } & \text { Ramosus } \\ \text { N } & \text { Nitrogen } \\ \text { P } & \text { Phosphate } \\ \text { CKX } & \text { CYTOKININ OXIDASE } \\ \text { CL } & \text { Carlactone } \\ \text { AMF } & \text { Arbuscular mycorrhizal fungus } \\ \text { TMB } & \text { Trimethylbutenolide } \\ \text { SW } & \text { Smoke-water } \\ & \\ & \end{array}$

\section{References}

1. AbuQamar, S.; Moustafa, K.; Tran, L.S.P. Mechanisms and strategies of plant defense against Botrytis cinerea. Crit. Rev. Biotechnol. 2017, 37, 262-274. [CrossRef] [PubMed]

2. Suzuki, N.; Rivero, R.M.; Shulaev, V.; Blumwald, E.; Mittler, R. Abiotic and biotic stress combinations. New Phytol. 2014, 203, 32-43. [CrossRef] [PubMed]

3. Zhu, J.K. Abiotic Stress Signaling and Responses in Plants. Cell 2016, 167, 313-324. [CrossRef] [PubMed]

4. Lesk, C.; Rowhani, P.; Ramankutty, N. Influence of extreme weather disasters on global crop production. Nature 2016, 529, 84-87. [CrossRef]

5. Boyer, J.S. Plant Productivity and Environment. Science 1982, 218, 443-448. [CrossRef]

6. Abdelrahman, M.; Jogaiah, S.; Burritt, D.J.; Tran, L.S.P. Legume genetic resources and transcriptome dynamics under abiotic stress conditions. Plant Cell Environ. 2018, 41, 1972-1983. [CrossRef] 
7. Li, W.Q.; Nguyen, K.H.; Chu, H.D.; Ha, C.V.; Watanabe, Y.; Osakabe, Y.; Leyva-Gonzalez, M.A.; Sato, M.; Toyooka, K.; Voges, L.; et al. The karrikin receptor KAI2 promotes drought resistance in Arabidopsis thaliana. PLoS Genet. 2017, 13. [CrossRef]

8. Kim, J.M.; To, T.K.; Matsui, A.; Tanoi, K.; Kobayashi, N.I.; Matsuda, F.; Habu, Y.; Ogawa, D.; Sakamoto, T.; Matsunaga, S.; et al. Acetate-mediated novel survival strategy against drought in plants. Nat. Plants 2017, 3. [CrossRef]

9. Xiong, L.M.; Schumaker, K.S.; Zhu, J.K. Cell signaling during cold, drought, and salt stress. Plant Cell 2002, 14, S165-S183. [CrossRef]

10. Fabregas, N.; Lozano-Elena, F.; Blasco-Escamez, D.; Tohge, T.; Martinez-Andujar, C.; Albacete, A.; Osorio, S.; Bustamante, M.; Riechmann, J.L.; Nomura, T.; et al. Overexpression of the vascular brassinosteroid receptor BRL3 confers drought resistance without penalizing plant growth. Nat. Commun. 2018, 9. [CrossRef]

11. Zhang, P.; Fan, Y.; Sun, X.P.; Chen, L.; Terzaghi, W.; Bucher, E.; Li, L.; Dai, M.Q. A large-scale circular RNA profiling reveals universal molecular mechanisms responsive to drought stress in maize and Arabidopsis. Plant J. 2019, 98, 697-713. [CrossRef] [PubMed]

12. Huang, X.Z.; Hou, L.Y.; Meng, J.J.; You, H.W.; Li, Z.; Gong, Z.Z.; Yang, S.H.; Shi, Y.T. The Antagonistic Action of Abscisic Acid and Cytokinin Signaling Mediates Drought Stress Response in Arabidopsis. Mol. Plant 2018, 11, 970-982. [CrossRef] [PubMed]

13. Yang, L.; Li, B.S.; Zheng, X.Y.; Li, J.G.; Yang, M.; Dong, X.N.; He, G.M.; An, C.C.; Deng, X.W. Salicylic acid biosynthesis is enhanced and contributes to increased biotrophic pathogen resistance in Arabidopsis hybrids. Nat. Commun. 2015, 6. [CrossRef]

14. Chen, J.N.; Nolan, T.M.; Ye, H.X.; Zhang, M.C.; Tong, H.N.; Xin, P.Y.; Chu, J.F.; Chu, C.C.; Li, Z.H.; Yin, Y.H. Arabidopsis WRKY46, WRKY54, and WRKY70 Transcription Factors Are Involved in Brassinosteroid-Regulated Plant Growth and Drought Responses. Plant Cell 2017, 29, 1425-1439. [CrossRef]

15. Ahmad, P.; Rasool, S.; Gul, A.; Sheikh, S.A.; Akram, N.A.; Ashraf, M.; Kazi, A.M.; Gucel, S. Jasmonates: Multifunctional Roles in Stress Tolerance. Front. Plant Sci. 2016, 7. [CrossRef]

16. Wasternack, C.; Hause, B. Jasmonates: Biosynthesis, perception, signal transduction and action in plant stress response, growth and development. An update to the 2007 review in Annals of Botany. Ann. Bot.-Lond. 2013, 111, 1021-1058. [CrossRef]

17. Choudhary, S.P.; Yu, J.Q.; Yamaguchi-Shinozaki, K.; Shinozaki, K.; Tran, L.S.P. Benefits of brassinosteroid crosstalk. Trends Plant Sci. 2012, 17, 594-605. [CrossRef]

18. Wani, S.H.; Kumar, V.; Shriram, V.; Sah, S.K. Phytohormones and their metabolic engineering for abiotic stress tolerance in crop plants. Crop J. 2016, 4, 162-176. [CrossRef]

19. Ha, S.; Vankova, R.; Yamaguchi-Shinozaki, K.; Shinozaki, K.; Tran, L.S.P. Cytokinins: Metabolism and function in plant adaptation to environmental stresses. Trends Plant Sci. 2012, 17, 172-179. [CrossRef]

20. Peleg, Z.; Blumwald, E. Hormone balance and abiotic stress tolerance in crop plants. Curr. Opin. Plant Biol. 2011, 14, 290-295. [CrossRef]

21. Pieterse, C.M.J.; Leon-Reyes, A.; Van der Ent, S.; Van Wees, S.C.M. Networking by small-molecule hormones in plant immunity. Nat. Chem. Biol. 2009, 5, 308-316. [CrossRef]

22. Robert-Seilaniantz, A.; Grant, M.; Jones, J.D.G. Hormone Crosstalk in Plant Disease and Defense: More Than Just JASMONATE-SALICYLATE Antagonism. Annu. Rev. Phytopathol. 2011, 49, 317-343. [CrossRef]

23. Santner, A.; Estelle, M. Recent advances and emerging trends in plant hormone signalling. Nature 2009, 459, 1071-1078. [CrossRef]

24. Netzly, D.H.; Riopel, J.L.; Ejeta, G.; Butler, L.G. Germination Stimulants of Witchweed (Striga-Asiatica) From Hydrophobic Root Exudate of Sorghum (Sorghum-Bicolor). Weed Sci. 1988, 36, 441-446. [CrossRef]

25. Xie, X.N.; Yoneyama, K.; Yoneyama, K. The Strigolactone Story. Annu. Rev. Phytopathol. 2010, 48, 93-117. [CrossRef]

26. Spallek, T.; Mutuku, M.; Shirasu, K. The genus Striga: A witch profile. Mol. Plant Pathol. 2013, 14, 861-869. [CrossRef]

27. Stanga, J.P.; Smith, S.M.; Briggs, W.R.; Nelson, D.C. SUPPRESSOR OF MORE AXILLARY GROWTH2 1 Controls Seed Germination and Seedling Development in Arabidopsis. Plant Physiol. 2013, 163, 318-330. [CrossRef] 
28. Umehara, M.; Hanada, A.; Yoshida, S.; Akiyama, K.; Arite, T.; Takeda-Kamiya, N.; Magome, H.; Kamiya, Y.; Shirasu, K.; Yoneyama, K.; et al. Inhibition of shoot branching by new terpenoid plant hormones. Nature 2008, 455, 195-200. [CrossRef]

29. Jiang, L.; Liu, X.; Xiong, G.S.; Liu, H.H.; Chen, F.L.; Wang, L.; Meng, X.B.; Liu, G.F.; Yu, H.; Yuan, Y.D.; et al. DWARF 53 acts as a repressor of strigolactone signalling in rice. Nature 2013, 504, 401-405. [CrossRef]

30. Chevalier, F.; Nieminen, K.; Sanchez-Ferrero, J.C.; Rodriguez, M.L.; Chagoyen, M.; Hardtke, C.S.; Cubas, P. Strigolactone Promotes Degradation of DWARF14, an alpha/beta Hydrolase Essential for Strigolactone Signaling in Arabidopsis. Plant Cell 2014, 26, 1134-1150. [CrossRef]

31. Wang, L.; Wang, B.; Jiang, L.; Liu, X.; Li, X.L.; Lu, Z.F.; Meng, X.B.; Wang, Y.H.; Smith, S.M.; Li, J.Y. Strigolactone Signaling in Arabidopsis Regulates Shoot Development by Targeting D53-Like SMXL Repressor Proteins for Ubiquitination and Degradation. Plant Cell 2015, 27, 3128-3142. [CrossRef] [PubMed]

32. Brewer, P.B.; Koltai, H.; Beveridge, C.A. Diverse Roles of Strigolactones in Plant Development. Mol. Plant 2013, 6, 18-28. [CrossRef] [PubMed]

33. Ueda, H.; Kusaba, M. Strigolactone Regulates Leaf Senescence in Concert with Ethylene in Arabidopsis. Plant Physiol. 2015, 169, 138-147. [CrossRef] [PubMed]

34. Akiyama, K.; Matsuzaki, K.; Hayashi, H. Plant sesquiterpenes induce hyphal branching in arbuscular mycorrhizal fungi. Nature 2005, 435, 824-827. [CrossRef] [PubMed]

35. Foo, E.; Yoneyama, K.; Hugill, C.J.; Quittenden, L.J.; Reid, J.B. Strigolactones and the Regulation of Pea Symbioses in Response to Nitrate and Phosphate Deficiency. Mol. Plant 2013, 6, 76-87. [CrossRef]

36. Lv, S.; Zhang, Y.H.; Li, C.; Liu, Z.J.; Yang, N.; Pan, L.X.; Wu, J.B.; Wang, J.J.; Yang, J.W.; Lv, Y.T.; et al. Strigolactone-triggered stomatal closure requires hydrogen peroxide synthesis and nitric oxide production in an abscisic acid-independent manner. New Phytol. 2018, 217, 290-304. [CrossRef]

37. Visentin, I.; Vitali, M.; Ferrero, M.; Zhang, Y.X.; Ruyter-Spira, C.; Novak, O.; Strnad, M.; Lovisolo, C.; Schubert, A.; Cardinale, F. Low levels of strigolactones in roots as a component of the systemic signal of drought stress in tomato. New Phytol. 2016, 212, 954-963. [CrossRef]

38. Ren, C.G.; Kong, C.C.; Xie, Z.H. Role of abscisic acid in strigolactone-induced salt stress tolerance in arbuscular mycorrhizal Sesbania cannabina seedlings. BMC Plant Biol. 2018, 18. [CrossRef]

39. Haider, I.; Andreo-Jimenez, B.; Bruno, M.; Bimbo, A.; Flokova, K.; Abuauf, H.; Ntui, V.O.; Guo, X.J.; Charnikhova, T.; Al-Babili, S.; et al. The interaction of strigolactones with abscisic acid during the drought response in rice. J. Exp. Bot. 2018, 69, 2403-2414. [CrossRef]

40. Ha, C.V.; Leyva-Gonzalez, M.A.; Osakabe, Y.; Tran, U.T.; Nishiyama, R.; Watanabe, Y.; Tanaka, M.; Seki, M.; Yamaguchi, S.; Dong, N.V.; et al. Positive regulatory role of strigolactone in plant responses to drought and salt stress. Proc. Natl. Acad. Sci. USA 2014, 111, 851-856. [CrossRef]

41. Ma, N.; Hu, C.; Wan, L.; Hu, Q.; Xiong, J.L.; Zhang, C.L. Strigolactones Improve Plant Growth, Photosynthesis, and Alleviate Oxidative Stress under Salinity in Rapeseed (Brassica napus L.) by Regulating Gene Expression. Front. Plant Sci. 2017, 8. [CrossRef] [PubMed]

42. Cooper, J.W.; Hu, Y.; Beyyoudh, L.; Dasgan, H.Y.; Kunert, K.; Beveridge, C.A.; Foyer, C.H. Strigolactones positively regulate chilling tolerance in pea and in Arabidopsis. Plant Cell Environ. 2018, 41, 1298-1310. [CrossRef] [PubMed]

43. Umehara, M.; Hanada, A.; Magome, H.; Takeda-Kamiya, N.; Yamaguchi, S. Contribution of Strigolactones to the Inhibition of Tiller Bud Outgrowth under Phosphate Deficiency in Rice. Plant Cell Physiol. 2010, 51, 1118-1126. [CrossRef] [PubMed]

44. Kohlen, W.; Charnikhova, T.; Liu, Q.; Bours, R.; Domagalska, M.A.; Beguerie, S.; Verstappen, F.; Leyser, O.; Bouwmeester, H.; Ruyter-Spira, C. Strigolactones Are Transported through the Xylem and Play a Key Role in Shoot Architectural Response to Phosphate Deficiency in Nonarbuscular Mycorrhizal Host Arabidopsis. Plant Physiol. 2011, 155, 974-987. [CrossRef]

45. Ruiz-Lozano, J.M.; Aroca, R.; Zamarreno, A.M.; Molina, S.; Andreo-Jimenez, B.; Porcel, R.; Garcia-Mina, J.M.; Ruyter-Spira, C.; Lopez-Raez, J.A. Arbuscular mycorrhizal symbiosis induces strigolactone biosynthesis under drought and improves drought tolerance in lettuce and tomato. Plant Cell Environ. 2016, 39, 441-452. [CrossRef]

46. Mayzlish-Gati, E.; De-Cuyper, C.; Goormachtig, S.; Beeckman, T.; Vuylsteke, M.; Brewer, P.B.; Beveridge, C.A.; Yermiyahu, U.; Kaplan, Y.; Enzer, Y.; et al. Strigolactones Are Involved in Root Response to Low Phosphate Conditions in Arabidopsis. Plant Physiol. 2012, 160, 1329-1341. [CrossRef] 
47. Bu, Q.Y.; Lv, T.X.; Shen, H.; Luong, P.; Wang, J.; Wang, Z.Y.; Huang, Z.G.; Xiao, L.T.; Engineer, C.; Kim, T.H.; et al. Regulation of Drought Tolerance by the F-Box Protein MAX2 in Arabidopsis(1[C][W][OPEN]). Plant Physiol. 2014, 164, 424-439. [CrossRef]

48. Andreo-Jimenez, B.; Ruyter-Spira, C.; Bouwmeester, H.J.; Lopez-Raez, J.A. Ecological relevance of strigolactones in nutrient uptake and other abiotic stresses, and in plant-microbe interactions below-ground. Plant Soil 2015, 394, 1-19. [CrossRef]

49. Min, Z.; Li, R.Y.; Chen, L.; Zhang, Y.; Li, Z.Y.; Liu, M.; Ju, Y.L.; Fang, Y.L. Alleviation of drought stress in grapevine by foliar-applied strigolactones. Plant Physiol. Biochem. 2019, 135, 99-110. [CrossRef]

50. Cardinale, F.; Krukowski, P.K.; Schubert, A.; Visentin, I. Strigolactones: Mediators of osmotic stress responses with a potential for agrochemical manipulation of crop resilience. J. Exp. Bot. 2018, 69, 2291-2303. [CrossRef]

51. Lopez-Raez, J.A.; Shirasu, K.; Foo, E. Strigolactones in Plant Interactions with Beneficial and Detrimental Organisms: The Yin and Yang. Trends Plant Sci. 2017, 22, 527-537. [CrossRef] [PubMed]

52. De Cuyper, C.; Struk, S.; Braem, L.; Gevaert, K.; De Jaeger, G.; Goormachtig, S. Strigolactones, karrikins and beyond. Plant Cell Environ. 2017, 40, 1691-1703. [CrossRef] [PubMed]

53. Al-Babili, S.; Bouwmeester, H.J. Strigolactones, a Novel Carotenoid-Derived Plant Hormone. Annu. Rev. Plant Biol. 2015, 66, 161-186. [CrossRef] [PubMed]

54. Flematti, G.R.; Ghisalberti, E.L.; Dixon, K.W.; Trengove, R.D. A compound from smoke that promotes seed germination. Science 2004, 305, 977. [CrossRef]

55. Nelson, D.C.; Scaffidi, A.; Dun, E.A.; Waters, M.T.; Flematti, G.R.; Dixon, K.W.; Beveridge, C.A.; Ghisalberti, E.L.; Smith, S.M. F-box protein MAX2 has dual roles in karrikin and strigolactone signaling in Arabidopsis thaliana. Proc. Natl. Acad. Sci. USA 2011, 108, 8897-8902. [CrossRef]

56. Flematti, G.R.; Ghisalberti, E.L.; Dixon, K.W.; Trengove, R.D. Identification of Alkyl Substituted 2H-Furo[2,3-c]pyran-2-ones as Germination Stimulants Present in Smoke. J. Agric. Food Chem. 2009, 57, 9475-9480. [CrossRef]

57. Nelson, D.C.; Flematti, G.R.; Ghisalberti, E.L.; Dixon, K.; Smith, S.M. Regulation of Seed Germination and Seedling Growth by Chemical Signals from Burning Vegetation. Annu. Rev. Plant Biol. 2012, 63, 107-130. [CrossRef]

58. Smith, S.M.; Li, J.Y. Signalling and responses to strigolactones and karrikins. Curr. Opin. Plant Biol. 2014, 21, 23-29. [CrossRef]

59. Ghebrehiwot, H.M.; Kulkarni, M.G.; Kirkman, K.P.; Van Staden, J. Smoke-water and a smoke-isolated butenolide improve germination and seedling vigour of Eragrostis tef (Zucc.) trotter under high temperature and low osmotic potential. J. Agron. Crop Sci. 2008, 194, 270-277. [CrossRef]

60. Kulkarni, M.G.; Sparg, S.G.; Light, M.E.; van Staden, J. Stimulation of rice (Oryza sativa L.) seedling vigour by smoke-water and butenolide. J. Agron. Crop Sci. 2006, 192, 395-398. [CrossRef]

61. Morffy, N.; Faure, L.; Nelson, D.C. Smoke and Hormone Mirrors: Action and Evolution of Karrikin and Strigolactone Signaling. Trends Genet. 2016, 32, 176-188. [CrossRef] [PubMed]

62. Wang, L.; Waters, M.T.; Smith, S.M. Karrikin-KAI2 signalling provides Arabidopsis seeds with tolerance to abiotic stress and inhibits germination under conditions unfavourable to seedling establishment. New Phytol. 2018, 219, 605-618. [CrossRef] [PubMed]

63. Banerjee, A.; Tripathi, D.K.; Roychoudhury, A. The karrikin "calisthenics": Can compounds derived from smoke help in stress tolerance? Physiol. Plant 2019, 165, 290-302. [CrossRef] [PubMed]

64. Jia, K.P.; Baz, L.; Al-Babili, S. From carotenoids to strigolactones. J. Exp. Bot. 2018, 69, 2189-2204. [CrossRef] [PubMed]

65. Lumba, S.; Holbrook-Smith, D.; McCourt, P. The perception of strigolactones in vascular plants. Nat. Chem. Biol. 2017, 13, 599-606. [CrossRef]

66. Alder, A.; Jamil, M.; Marzorati, M.; Bruno, M.; Vermathen, M.; Bigler, P.; Ghisla, S.; Bouwmeester, H.; Beyer, P.; Al-Babili, S. The Path from beta-Carotene to Carlactone, a Strigolactone-Like Plant Hormone. Science 2012, 335, 1348-1351. [CrossRef]

67. Lin, H.; Wang, R.X.; Qian, Q.; Yan, M.X.; Meng, X.B.; Fu, Z.M.; Yan, C.Y.; Jiang, B.; Su, Z.; Li, J.Y.; et al. DWARF27, an Iron-Containing Protein Required for the Biosynthesis of Strigolactones, Regulates Rice Tiller Bud Outgrowth. Plant Cell 2009, 21, 1512-1525. [CrossRef] 
68. Waters, M.T.; Brewer, P.B.; Bussell, J.D.; Smith, S.M.; Beveridge, C.A. The Arabidopsis Ortholog of Rice DWARF27 Acts Upstream of MAX1 in the Control of Plant Development by Strigolactones. Plant Physiol. 2012, 159, 1073-1085. [CrossRef]

69. Booker, J.; Auldridge, M.; Wills, S.; McCarty, D.; Klee, H.; Leyser, O. MAX3/CCD7 is a carotenoid cleavage dioxygenase required for the synthesis of a novel plant signaling molecule. Curr. Biol. 2004, 14, 1232-1238. [CrossRef]

70. Drummond, R.S.M.; Martinez-Sanchez, N.M.; Janssen, B.J.; Templeton, K.R.; Simons, J.L.; Quinn, B.D.; Karunairetnam, S.; Snowden, K.C. Petunia hybrida CAROTENOID CLEAVAGE DIOXYGENASE7 Is Involved in the Production of Negative and Positive Branching Signals in Petunia. Plant Physiol. 2009, 151, 1867-1877. [CrossRef]

71. Zou, J.H.; Zhang, S.Y.; Zhang, W.P.; Li, G.; Chen, Z.X.; Zhai, W.X.; Zhao, X.F.; Pan, X.B.; Xie, Q.; Zhu, L.H. The rice HIGH-TILLERING DWARF1 encoding an ortholog of Arabidopsis MAX3 is required for negative regulation of the outgrowth of axillary buds. Plant J. 2006, 48, 687-696. [CrossRef] [PubMed]

72. Arite, T.; Iwata, H.; Ohshima, K.; Maekawa, M.; Nakajima, M.; Kojima, M.; Sakakibara, H.; Kyozuka, J. DWARF10, an RMS1/MAX4/DAD1 ortholog, controls lateral bud outgrowth in rice. Plant J. 2007, 51, 1019-1029. [CrossRef] [PubMed]

73. Simons, J.L.; Napoli, C.A.; Janssen, B.J.; Plummer, K.M.; Snowden, K.C. Analysis of the DECREASED APICAL DOMINANCE genes of petunia in the control of axillary branching. Plant Physiol. 2007, 143, 697-706. [CrossRef] [PubMed]

74. Snowden, K.C.; Simkin, A.J.; Janssen, B.J.; Templeton, K.R.; Loucas, H.M.; Simons, J.L.; Karunairetnam, S.; Gleave, A.P.; Clark, D.G.; Klee, H.J. The Decreased apical dominance 1/petunia hybrida carotenoid cleavage dioxygenase8 gene affects branch production and plays a role in leaf senescence, root growth, and flower development. Plant Cell 2005, 17, 746-759. [CrossRef] [PubMed]

75. Sorefan, K.; Booker, J.; Haurogne, K.; Goussot, M.; Bainbridge, K.; Foo, E.; Chatfield, S.; Ward, S.; Beveridge, C.; Rameau, C.; et al. MAX4 and RMS1 are orthologous dioxygenase-like genes that regulate shoot branching in Arabidopsis and pea. Genes Dev. 2003, 17, 1469-1474. [CrossRef]

76. Seto, Y.; Sado, A.; Asami, K.; Hanada, A.; Umehara, M.; Akiyama, K.; Yamaguchi, S. Carlactone is an endogenous biosynthetic precursor for strigolactones. Proc. Natl. Acad. Sci. USA 2014, 111, 1640-1645. [CrossRef]

77. Booker, J.; Sieberer, T.; Wright, W.; Williamson, L.; Willett, B.; Stirnberg, P.; Turnbull, C.; Srinivasan, M.; Goddard, P.; Leyser, O. MAX1 encodes a cytochrome P450 family member that acts downstream of MAX3/4 to produce a carotenoid-derived branch-inhibiting hormone. Dev. Cell 2005, 8, 443-449. [CrossRef]

78. Drummond, R.S.M.; Sheehan, H.; Simons, J.L.; Martinez-Sanchez, N.M.; Turner, R.M.; Putterill, J.; Snowden, K.C. The expression of petunia strigolactone pathway genes is altered as part of the endogenous developmental program. Front. Plant Sci. 2012, 2. [CrossRef]

79. Zhang, Y.X.; van Dijk, A.D.J.; Scaffidi, A.; Flematti, G.R.; Hofmann, M.; Charnikhova, T.; Verstappen, F.; Hepworth, J.; van der Krol, S.; Leyser, O.; et al. Rice cytochrome P450 MAX1 homologs catalyze distinct steps in strigolactone biosynthesis. Nat. Chem. Biol. 2014, 10, 1028-1033. [CrossRef]

80. Brewer, P.B.; Yoneyama, K.; Filardo, F.; Meyers, E.; Scaffidi, A.; Frickey, T.; Akiyama, K.; Seto, Y.; Dun, E.A.; Cremer, J.E.; et al. LATERAL BRANCHING OXIDOREDUCTASE acts in the final stages of strigolactone biosynthesis in Arabidopsis. Proc. Natl. Acad. Sci. USA 2016, 113, 6301-6306. [CrossRef]

81. Flematti, G.R.; Scaffidi, A.; Dixon, K.W.; Smith, S.M.; Ghisalberti, E.L. Production of the Seed Germination Stimulant Karrikinolide from Combustion of Simple Carbohydrates. J. Agric. Food Chem. 2011, 59, 1195-1198. [CrossRef] [PubMed]

82. Nelson, D.C.; Riseborough, J.A.; Flematti, G.R.; Stevens, J.; Ghisalberti, E.L.; Dixon, K.W.; Smith, S.M. Karrikins Discovered in Smoke Trigger Arabidopsis Seed Germination by a Mechanism Requiring Gibberellic Acid Synthesis and Light. Plant Physiol. 2009, 149, 863-873. [CrossRef] [PubMed]

83. Waters, M.T.; Scaffidi, A.; Sun, Y.M.K.; Flematti, G.R.; Smith, S.M. The karrikin response system of Arabidopsis. Plant J. 2014, 79, 623-631. [CrossRef] [PubMed]

84. Zhao, L.H.; Zhou, X.E.; Wu, Z.S.; Yi, W.; Xu, Y.; Li, S.L.; Xu, T.H.; Liu, Y.; Chen, R.Z.; Kovach, A.; et al. Crystal structures of two phytohormone signal-transducing alpha/beta hydrolases: Karrikin-signaling KAI2 and strigolactone-signaling DWARF14. Cell Res. 2013, 23, 436-439. [CrossRef] [PubMed] 
85. Yao, R.F.; Ming, Z.H.; Yan, L.M.; Li, S.H.; Wang, F.; Ma, S.; Yu, C.T.; Yang, M.; Chen, L.; Chen, L.H.; et al. DWARF14 is a non-canonical hormone receptor for strigolactone. Nature 2016, 536, 469-473. [CrossRef]

86. Waters, M.T.; Gutjahr, C.; Bennett, T.; Nelson, D.C. Strigolactone Signaling and Evolution. Annu. Rev. Plant Biol. 2017, 68, 291-322. [CrossRef]

87. Nakamura, H.; Xue, Y.L.; Miyakawa, T.; Hou, F.; Qin, H.M.; Fukui, K.; Shi, X.; Ito, E.; Ito, S.; Park, S.H.; et al. Molecular mechanism of strigolactone perception by DWARF14. Nat. Commun. 2013, 4. [CrossRef]

88. Zhou, F.; Lin, Q.B.; Zhu, L.H.; Ren, Y.L.; Zhou, K.N.; Shabek, N.; Wu, F.Q.; Mao, H.B.; Dong, W.; Gan, L.; et al. D14-SCFD3-dependent degradation of D53 regulates strigolactone signalling. Nature 2013, 504, 406. [CrossRef]

89. Soundappan, I.; Bennett, T.; Morffy, N.; Liang, Y.Y.; Stang, J.P.; Abbas, A.; Leyser, O.; Nelson, D.C. SMAX1-LIKE/D53 Family Members Enable Distinct MAX2-Dependent Responses to Strigolactones and Karrikins in Arabidopsis. Plant Cell 2015, 27, 3143-3159. [CrossRef]

90. Guo, Y.X.; Zheng, Z.Y.; La Clair, J.J.; Chory, J.; Noel, J.P. Smoke-derived karrikin perception by the alpha/beta-hydrolase KAI2 from Arabidopsis. Proc. Natl. Acad. Sci. USA 2013, 110, 8284-8289. [CrossRef]

91. Kagiyama, M.; Hirano, Y.; Mori, T.; Kim, S.Y.; Kyozuka, J.; Seto, Y.; Yamaguchi, S.; Hakoshima, T. Structures of D14 and D14L in the strigolactone and karrikin signaling pathways. Genes Cells 2013, 18, 147-160. [CrossRef] [PubMed]

92. Waters, M.T.; Scaffidi, A.; Moulin, S.L.Y.; Sun, Y.M.K.; Flematti, G.R.; Smith, S.M. A Selaginella moellendorffii Ortholog of KARRIKIN INSENSITIVE2 Functions in Arabidopsis Development but Cannot Mediate Responses to Karrikins or Strigolactones. Plant Cell 2015, 27, 1925-1944. [CrossRef] [PubMed]

93. Waters, M.T.; Scaffidi, A.; Flematti, G.; Smith, S.M. Substrate-Induced Degradation of the alpha/beta-Fold Hydrolase KARRIKIN INSENSITIVE2 Requires a Functional Catalytic Triad but Is Independent of MAX2. Mol. Plant 2015, 8, 814-817. [CrossRef] [PubMed]

94. Machin, D.C.; Hamon-Josse, M.; Bennett, T. Fellowship of the rings: A saga of strigolactones and other small signals. New Phytol. 2019. [CrossRef] [PubMed]

95. Gupta, S.; Plackova, L.; Kulkarni, M.G.; Dolezal, K.; Van Staden, J. Role of Smoke Stimulatory and Inhibitory Biomolecules in Phytochrome-Regulated Seed Germination of Lactuca sativa. Plant Physiol. 2019, 181, 458-470. [CrossRef]

96. Toh, S.; Kamiya, Y.; Kawakami, N.; Nambara, E.; McCourt, P.; Tsuchiya, Y. Thermoinhibition Uncovers a Role for Strigolactones in Arabidopsis Seed Germination. Plant Cell Physiol. 2012, 53, 107-117. [CrossRef]

97. Vesty, E.F.; Saidi, Y.; Moody, L.A.; Holloway, D.; Whitbread, A.; Needs, S.; Choudhary, A.; Burns, B.; McLeod, D.; Bradshaw, S.J.; et al. The decision to germinate is regulated by divergent molecular networks in spores and seeds. New Phytol. 2016, 211, 952-966. [CrossRef]

98. Nelson, D.C.; Flematti, G.R.; Riseborough, J.A.; Ghisalberti, E.L.; Dixon, K.W.; Smith, S.M. Karrikins enhance light responses during germination and seedling development in Arabidopsis thaliana. Proc. Natl. Acad. Sci. USA 2010, 107, 7095-7100. [CrossRef]

99. Meng, Y.J.; Chen, F.; Shuai, H.W.; Luo, X.F.; Ding, J.; Tang, S.W.; Xu, S.S.; Liu, J.W.; Liu, W.G.; Du, J.B.; et al. Karrikins delay soybean seed germination by mediating abscisic acid and gibberellin biogenesis under shaded conditions. Sci. Rep. 2016, 6. [CrossRef]

100. Stirnberg, P.; van de Sande, K.; Leyser, H.M.O. MAX1 and MAX2 control shoot lateral branching in Arabidopsis. Development 2002, 129, 1131-1141.

101. Gomez-Roldan, V.; Fermas, S.; Brewer, P.B.; Puech-Pages, V.; Dun, E.A.; Pillot, J.P.; Letisse, F.; Matusova, R.; Danoun, S.; Portais, J.C.; et al. Strigolactone inhibition of shoot branching. Nature 2008, 455, 189-194. [CrossRef] [PubMed]

102. Jamil, M.; Charnikhova, T.; Houshyani, B.; van Ast, A.; Bouwmeester, H.J. Genetic variation in strigolactone production and tillering in rice and its effect on Striga hermonthica infection. Planta 2012, 235, 473-484. [CrossRef] [PubMed]

103. Tan, M.; Li, G.F.; Chen, X.L.; Xing, L.B.; Ma, J.J.; Zhang, D.; Ge, H.J.; Han, M.Y.; Sha, G.L.; An, N. Role of Cytokinin, Strigolactone, and Auxin Export on Outgrowth of Axillary Buds in Apple. Front. Plant Sci. 2019, 10. [CrossRef] [PubMed]

104. Mouchel, C.F.; Leyser, O. Novel phytohormones involved in long-range signaling. Curr. Opin. Plant Biol. 2007, 10, 473-476. [CrossRef] [PubMed] 
105. Song, X.G.; Lu, Z.F.; Yu, H.; Shao, G.N.; Xiong, J.S.; Meng, X.B.; Jing, Y.H.; Liu, G.F.; Xiong, G.S.; Duan, J.B.; et al. IPA1 functions as a downstream transcription factor repressed by D53 in strigolactone signaling in rice. Cell Res. 2017, 27, 1128-1141. [CrossRef] [PubMed]

106. Proust, H.; Hoffmann, B.; Xie, X.N.; Yoneyama, K.; Schaefer, D.G.; Yoneyama, K.; Nogue, F.; Rameau, C. Strigolactones regulate protonema branching and act as a quorum sensing-like signal in the moss Physcomitrella patens. Development 2011, 138, 1531-1539. [CrossRef]

107. Kretzschmar, T.; Kohlen, W.; Sasse, J.; Borghi, L.; Schlegel, M.; Bachelier, J.B.; Reinhardt, D.; Bours, R.; Bouwmeester, H.J.; Martinoia, E. A petunia ABC protein controls strigolactone-dependent symbiotic signalling and branching. Nature 2012, 483, 341-344. [CrossRef]

108. Xie, X.D.; Wang, G.H.; Yang, L.; Cheng, T.C.; Gao, J.P.; Wu, Y.Q.; Xia, Q.Y. Cloning and characterization of a novel Nicotiana tabacum ABC transporter involved in shoot branching. Physiol. Plant 2015, 153, $299-306$. [CrossRef]

109. Takeda, T.; Suwa, Y.; Suzuki, M.; Kitano, H.; Ueguchi-Tanaka, M.; Ashikari, M.; Matsuoka, M.; Ueguchi, C. The OsTB1 gene negatively regulates lateral branching in rice. Plant J. 2003, 33, 513-520. [CrossRef]

110. Aguilar-Martinez, J.A.; Poza-Carrion, C.; Cubas, P. Arabidopsis BRANCHED1 acts as an integrator of branching signals within axillary buds. Plant Cell 2007, 19, 458-472. [CrossRef]

111. Braun, N.; de Saint Germain, A.; Pillot, J.P.; Boutet-Mercey, S.; Dalmais, M.; Antoniadi, I.; Li, X.; Maia-Grondard, A.; Le Signor, C.; Bouteiller, N.; et al. The Pea TCP Transcription Factor PsBRC1 Acts Downstream of Strigolactones to Control Shoot Branching. Plant Physiol. 2012, 158, 225-238. [CrossRef]

112. Martin-Trillo, M.; Grandio, E.G.; Serra, F.; Marcel, F.; Rodriguez-Buey, M.L.; Schmitz, G.; Theres, K.; Bendahmane, A.; Dopazo, H.; Cubas, P. Role of tomato BRANCHED1-like genes in the control of shoot branching. Plant J. 2011, 67, 701-714. [CrossRef]

113. Nicolas, M.; Rodriguez-Buey, M.L.; Franco-Zorrilla, J.M.; Cubas, P. A Recently Evolved Alternative Splice Site in the BRANCHED1a Gene Controls Potato Plant Architecture. Curr. Biol. 2015, 25, 1799-1809. [CrossRef]

114. Agusti, J.; Herold, S.; Schwarz, M.; Sanchez, P.; Ljung, K.; Dun, E.A.; Brewer, P.B.; Beveridge, C.A.; Sieberer, T.; Sehr, E.M.; et al. Strigolactone signaling is required for auxin-dependent stimulation of secondary growth in plants. Proc. Natl. Acad. Sci. USA 2011, 108, 20242-20247. [CrossRef]

115. Zou, X.; Wang, Q.; Chen, P.S.; Yin, C.X.; Lin, Y.J. Strigolactones regulate shoot elongation by mediating gibberellin metabolism and signaling in rice (Oryza sativa L.). J. Plant Physiol. 2019, 237, 72-79. [CrossRef]

116. Kapulnik, Y.; Delaux, P.M.; Resnick, N.; Mayzlish-Gati, E.; Wininger, S.; Bhattacharya, C.; Sejalon-Delmas, N.; Combier, J.P.; Becard, G.; Belausov, E.; et al. Strigolactones affect lateral root formation and root-hair elongation in Arabidopsis. Planta 2011, 233, 209-216. [CrossRef]

117. Foo, E.; Davies, N.W. Strigolactones promote nodulation in pea. Planta 2011, 234, 1073-1081. [CrossRef]

118. Arite, T.; Kameoka, H.; Kyozuka, J. Strigolactone Positively Controls Crown Root Elongation in Rice. J. Plant Growth Regul. 2012, 31, 165-172. [CrossRef]

119. Rasmussen, A.; Mason, M.G.; De Cuyper, C.; Brewer, P.B.; Herold, S.; Agusti, J.; Geelen, D.; Greb, T.; Goormachtig, S.; Beeckman, T.; et al. Strigolactones Suppress Adventitious Rooting in Arabidopsis and Pea. Plant Physiol. 2012, 158, 1976-1987. [CrossRef]

120. Kohlen, W.; Charnikhova, T.; Lammers, M.; Pollina, T.; Toth, P.; Haider, I.; Pozo, M.J.; de Maagd, R.A.; Ruyter-Spira, C.; Bouwmeester, H.J.; et al. The tomato CAROTENOID CLEAVAGE DIOXYGENASE8 (SICCD8) regulates rhizosphere signaling, plant architecture and affects reproductive development through strigolactone biosynthesis. New Phytol. 2012, 196, 535-547. [CrossRef]

121. Urquhart, S.; Foo, E.; Reid, J.B. The role of strigolactones in photomorphogenesis of pea is limited to adventitious rooting. Physiol. Plant 2015, 153, 392-402. [CrossRef]

122. Liu, G.; Stirnemann, M.; Gubeli, C.; Egloff, S.; Courty, P.E.; Aubry, S.; Vandenbussche, M.; Morel, P.; Reinhardt, D.; Martinoia, E.; et al. Strigolactones Play an Important Role in Shaping Exodermal Morphology via a KAI2-Dependent Pathway. iScience 2019, 17, 144-154. [CrossRef]

123. Villaecija-Aguilar, J.A.; Hamon-Josse, M.; Carbonnel, S.; Kretschmar, A.; Schmid, C.; Dawid, C.; Bennett, T.; Gutjahr, C. SMAX1/SMXL2 regulate root and root hair development downstream of KAI2-mediated signalling in Arabidopsis. PLoS Genet. 2019, 15. [CrossRef]

124. Besserer, A.; Puech-Pages, V.; Kiefer, P.; Gomez-Roldan, V.; Jauneau, A.; Roy, S.; Portais, J.C.; Roux, C.; Becard, G.; Sejalon-Delmas, N. Strigolactones stimulate arbuscular mycorrhizal fungi by activating mitochondria. PLoS Biol. 2006, 4, 1239-1247. [CrossRef] 
125. Besserer, A.; Becard, G.; Jauneau, A.; Roux, C.; Sejalon-Delmas, N. GR24, a synthetic analog of strigolactones, stimulates the mitosis and growth of the arbuscular mycorrhizal fungus Gigaspora rosea by boosting its energy metabolism. Plant Physiol. 2008, 148, 402-413. [CrossRef]

126. Foo, E.; Reid, J.B. Strigolactones: New Physiological Roles for an Ancient Signal. J. Plant Growth Regul. 2013, 32, 429-442. [CrossRef]

127. Breuillin, F.; Schramm, J.; Hajirezaei, M.; Ahkami, A.; Favre, P.; Druege, U.; Hause, B.; Bucher, M.; Kretzschmar, T.; Bossolini, E.; et al. Phosphate systemically inhibits development of arbuscular mycorrhiza in Petunia hybrida and represses genes involved in mycorrhizal functioning. Plant J. 2010, 64, 1002-1017. [CrossRef]

128. Lopez-Raez, J.A.; Charnikhova, T.; Fernandez, I.; Bouwmeester, H.; Pozo, M.J. Arbuscular mycorrhizal symbiosis decreases strigolactone production in tomato. J. Plant Physiol. 2011, 168, 294-297. [CrossRef]

129. Fernandez-Aparicio, M.; Garcia-Garrido, J.M.; Ocampo, J.A.; Rubiales, D. Colonisation of field pea roots by arbuscular mycorrhizal fungi reduces Orobanche and Phelipanche species seed germination. Weed Res. 2010, 50, 262-268. [CrossRef]

130. Catford, J.G.; Staehelin, C.; Lerat, S.; Piche, Y.; Vierheilig, H. Suppression of arbuscular mycorrhizal colonization and nodulation in split-root systems of alfalfa after pre-inoculation and treatment with Nod factors. J. Exp. Bot. 2003, 54, 1481-1487. [CrossRef]

131. Ahmad, M.Z.; Rehman, N.U.U.; Yu, S.; Zhou, Y.; Haq, B.U.; Wang, J.; Li, P.; Zeng, Z.; Zhao, J. GmMAX2-D14 and -KAI interactions-mediated SL and KAR signaling play essential roles in soybean root nodulation. Plant J. 2019. [CrossRef] [PubMed]

132. Waters, M.T.; Nelson, D.C.; Scaffidi, A.; Flematti, G.R.; Sun, Y.K.M.; Dixon, K.W.; Smith, S.M. Specialisation within the DWARF14 protein family confers distinct responses to karrikins and strigolactones in Arabidopsis. Development 2012, 139, 1285-1295. [CrossRef] [PubMed]

133. Gutjahr, C.; Gobbato, E.; Choi, J.; Riemann, M.; Johnston, M.G.; Summers, W.; Carbonnel, S.; Mansfield, C.; Yang, S.Y.; Nadal, M.; et al. Rice perception of symbiotic arbuscular mycorrhizal fungi requires the karrikin receptor complex. Science 2015, 350, 1521-1524. [CrossRef] [PubMed]

134. Jia, K.P.; Luo, Q.; He, S.B.; Lu, X.D.; Yang, H.Q. Strigolactone-Regulated Hypocotyl Elongation Is Dependent on Cryptochrome and Phytochrome Signaling Pathways in Arabidopsis. Mol. Plant 2014, 7, 528-540. [CrossRef]

135. Tsuchiya, Y.; Vidaurre, D.; Toh, S.; Hanada, A.; Nambara, E.; Kamiya, Y.; Yamaguchi, S.; McCourt, P. A small-molecule screen identifies new functions for the plant hormone strigolactone. Nat. Chem. Biol. 2010, 6, 741-749. [CrossRef]

136. Hamiaux, C.; Drummond, R.S.M.; Janssen, B.J.; Ledger, S.E.; Cooney, J.M.; Newcomb, R.D.; Snowden, K.C. DAD2 Is an alpha/beta Hydrolase Likely to Be Involved in the Perception of the Plant Branching Hormone, Strigolactone. Curr. Biol. 2012, 22, 2032-2036. [CrossRef]

137. Ruyter-Spira, C.; Kohlen, W.; Charnikhova, T.; van Zeijl, A.; van Bezouwen, L.; de Ruijter, N.; Cardoso, C.; Lopez-Raez, J.A.; Matusova, R.; Bours, R.; et al. Physiological Effects of the Synthetic Strigolactone Analog GR24 on Root System Architecture in Arabidopsis: Another Belowground Role for Strigolactones? Plant Physiol. 2011, 155, 721-734. [CrossRef]

138. van Rongen, M.; Bennett, T.; Ticchiarelli, F.; Leyser, O. Connective auxin transport contributes to strigolactone-mediated shoot branching control independent of the transcription factor BRC1. PLoS Genet. 2019, 15. [CrossRef]

139. Ito, S.; Yamagami, D.; Umehara, M.; Hanada, A.; Yoshida, S.; Sasaki, Y.; Yajima, S.; Kyozuka, J.; Ueguchi-Tanaka, M.; Matsuoka, M.; et al. Regulation of Strigolactone Biosynthesis by Gibberellin Signaling. Plant Physiol. 2017, 174, 1250-1259. [CrossRef]

140. Lopez-Raez, J.A.; Kohlen, W.; Charnikhova, T.; Mulder, P.; Undas, A.K.; Sergeant, M.J.; Verstappen, F.; Bugg, T.D.H.; Thompson, A.J.; Ruyter-Spira, C.; et al. Does abscisic acid affect strigolactone biosynthesis? New Phytol. 2010, 187, 343-354. [CrossRef]

141. Shen, H.; Zhu, L.; Bu, Q.Y.; Huq, E. MAX2 Affects Multiple Hormones to Promote Photomorphogenesis. Mol. Plant 2012, 5, 750-762. [CrossRef]

142. Liu, J.W.; He, H.Z.; Vitali, M.; Visentin, I.; Charnikhova, T.; Haider, I.; Schubert, A.; Ruyter-Spira, C.; Bouwmeester, H.J.; Lovisolo, C.; et al. Osmotic stress represses strigolactone biosynthesis in Lotus japonicus 
roots: Exploring the interaction between strigolactones and ABA under abiotic stress. Planta 2015, 241, 1435-1451. [CrossRef]

143. Rodriguez, J.A.M.; Morcillo, R.L.; Vierheilig, H.; Ocampo, J.A.; Ludwig-Muller, J.; Garrido, J.M.G. Mycorrhization of the notabilis and sitiens tomato mutants in relation to abscisic acid and ethylene contents. J. Plant Physiol. 2010, 167, 606-613. [CrossRef]

144. Kapulnik, Y.; Resnick, N.; Mayzlish-Gati, E.; Kaplan, Y.; Wininger, S.; Hershenhorn, J.; Koltai, H. Strigolactones interact with ethylene and auxin in regulating root-hair elongation in Arabidopsis. J. Exp. Bot. 2011, 62, 2915-2924. [CrossRef]

145. Yamada, Y.; Furusawa, S.; Nagasaka, S.; Shimomura, K.; Yamaguchi, S.; Umehara, M. Strigolactone signaling regulates rice leaf senescence in response to a phosphate deficiency. Planta 2014, 240, 399-408. [CrossRef]

146. Dun, E.A.; de Saint Germain, A.; Rameau, C.; Beveridge, C.A. Antagonistic Action of Strigolactone and Cytokinin in Bud Outgrowth Control. Plant Physiol. 2012, 158, 487-498. [CrossRef]

147. Minakuchi, K.; Kameoka, H.; Yasuno, N.; Umehara, M.; Luo, L.; Kobayashi, K.; Hanada, A.; Ueno, K.; Asami, T.; Yamaguchi, S.; et al. FINE CULM1 (FC1) Works Downstream of Strigolactones to Inhibit the Outgrowth of Axillary Buds in Rice. Plant Cell Physiol. 2010, 51, 1127-1135. [CrossRef]

148. Duan, J.B.; Yu, H.; Yuan, K.; Liao, Z.G.; Meng, X.B.; Jing, Y.H.; Liu, G.F.; Chu, J.F.; Li, J.Y. Strigolactone promotes cytokinin degradation through transcriptional activation of CYTOKININ OXIDASE/DEHYDROGENASE 9 in rice. Proc. Natl. Acad. Sci. USA 2019, 116, 14319-14324. [CrossRef]

149. Jiang, L.X.; Matthys, C.; Marquez-Garcia, B.; De Cuyper, C.; Smet, L.; De Keyser, A.; Boyer, F.D.; Beeckman, T.; Depuydt, S.; Goormachtig, S. Strigolactones spatially influence lateral root development through the cytokinin signaling network. J. Exp. Bot. 2016, 67, 379-389. [CrossRef]

150. Wang, Y.; Sun, S.Y.; Zhu, W.J.; Jia, K.P.; Yang, H.Q.; Wang, X.L. Strigolactone/MAX2-Induced Degradation of Brassinosteroid Transcriptional Effector BES1 Regulates Shoot Branching. Dev. Cell 2013, 27, 681-688. [CrossRef]

151. Reinhardt, D.; Pesce, E.R.; Stieger, P.; Mandel, T.; Baltensperger, K.; Bennett, M.; Traas, J.; Friml, J.; Kuhlemeier, C. Regulation of phyllotaxis by polar auxin transport. Nature 2003, 426, 255-260. [CrossRef] [PubMed]

152. Wang, R.H.; Estelle, M. Diversity and specificity: Auxin perception and signaling through the TIR1/AFB pathway. Curr. Opin. Plant Biol. 2014, 21, 51-58. [CrossRef] [PubMed]

153. Szemenyei, H.; Hannon, M.; Long, J.A. TOPLESS mediates auxin-dependent transcriptional repression during Arabidopsis embryogenesis. Science 2008, 319, 1384-1386. [CrossRef] [PubMed]

154. Brewer, P.B.; Dun, E.A.; Ferguson, B.J.; Rameau, C.; Beveridge, C.A. Strigolactone Acts Downstream of Auxin to Regulate Bud Outgrowth in Pea and Arabidopsis. Plant Physiol. 2009, 150, 482-493. [CrossRef] [PubMed]

155. Zha, M.; Imran, M.; Wang, Y.; Xu, J.; Ding, Y.; Wang, S.H. Transcriptome analysis revealed the interaction among strigolactones, auxin, and cytokinin in controlling the shoot branching of rice. Plant Cell Rep. 2019, 38, 279-293. [CrossRef]

156. Sun, H.W.; Tao, J.Y.; Liu, S.J.; Huang, S.J.; Chen, S.; Xie, X.N.; Yoneyama, K.; Zhang, Y.L.; Xu, G.H. Strigolactones are involved in phosphate- and nitrate-deficiency-induced root development and auxin transport in rice. J. Exp. Bot. 2014, 65, 6735-6746. [CrossRef]

157. Bennett, T.; Sieberer, T.; Willett, B.; Booker, J.; Luschnig, C.; Leyser, O. The Arabidopsis MAX pathway controls shoot branching by regulating auxin transport. Curr. Biol. 2006, 16, 553-563. [CrossRef]

158. Kumar, M.; Pandya-Kumar, N.; Dam, A.; Haor, H.; Mayzlish-Gati, E.; Belausov, E.; Wininger, S.; Abu-Abied, M.; McErlean, C.S.P.; Bromhead, L.J.; et al. Arabidopsis response to low-phosphate conditions includes active changes in actin filaments and PIN2 polarization and is dependent on strigolactone signalling. J. Exp. Bot. 2015, 66, 1499-1510. [CrossRef]

159. Crawford, S.; Shinohara, N.; Sieberer, T.; Williamson, L.; George, G.; Hepworth, J.; Muller, D.; Domagalska, M.A.; Leyser, O. Strigolactones enhance competition between shoot branches by dampening auxin transport. Development 2010, 137, 2905-2913. [CrossRef]

160. Shinohara, N.; Taylor, C.; Leyser, O. Strigolactone Can Promote or Inhibit Shoot Branching by Triggering Rapid Depletion of the Auxin Efflux Protein PIN1 from the Plasma Membrane. PLoS Biol. 2013, 11. [CrossRef]

161. Koltai, H. Strigolactones are regulators of root development. New Phytol. 2011, 190, 545-549. [CrossRef] [PubMed] 
162. Koltai, H.; Dor, E.; Hershenhorn, J.; Joel, D.M.; Weininger, S.; Lekalla, S.; Shealtiel, H.; Bhattacharya, C.; Eliahu, E.; Resnick, N.; et al. Strigolactones' Effect on Root Growth and Root-Hair Elongation May Be Mediated by Auxin-Efflux Carriers. J. Plant Growth Regul. 2010, 29, 129-136. [CrossRef]

163. Bertheloot, J.; Barbier, F.; Boudon, F.; Perez-Garcia, M.D.; Peron, T.; Citerne, S.; Dun, E.; Beveridge, C.; Godin, C.; Sakr, S. Sugar availability suppresses the auxin-induced strigolactone pathway to promote bud outgrowth. New Phytol. 2019. [CrossRef] [PubMed]

164. Hayward, A.; Stirnberg, P.; Beveridge, C.; Leyser, O. Interactions between Auxin and Strigolactone in Shoot Branching Control. Plant Physiol. 2009, 151, 400-412. [CrossRef]

165. Xu, J.X.; Zha, M.R.; Li, Y.; Ding, Y.F.; Chen, L.; Ding, C.Q.; Wang, S.H. The interaction between nitrogen availability and auxin, cytokinin, and strigolactone in the control of shoot branching in rice (Oryza sativa L.). Plant Cell Rep. 2015, 34, 1647-1662. [CrossRef]

166. Cheng, X.; Ruyter-Spira, C.; Bouwmeester, H. The interaction between strigolactones and other plant hormones in the regulation of plant development. Front. Plant Sci. 2013, 4. [CrossRef]

167. Meng, Y.J.; Shuai, H.W.; Luo, X.F.; Chen, F.; Zhou, W.G.; Yang, W.Y.; Shu, K. Karrikins: Regulators Involved in Phytohormone Signaling Networks during Seed Germination and Seedling Development. Front. Plant Sci. 2017, 7. [CrossRef]

168. Yamaguchi, S. Gibberellin metabolism and its regulation. Annu. Rev. Plant Biol. 2008, 59, 225-251. [CrossRef]

169. Lo, S.F.; Yang, S.Y.; Chen, K.T.; Hsing, Y.L.; Zeevaart, J.A.D.; Chen, L.J.; Yu, S.M. A Novel Class of Gibberellin 2-Oxidases Control Semidwarfism, Tillering, and Root Development in Rice. Plant Cell 2008, 20, 2603-2618. [CrossRef]

170. Silverstone, A.L.; Chang, C.W.; Krol, E.; Sun, T.P. Developmental regulation of the gibberellin biosynthetic gene GA1 in Arabidopsis thaliana. Plant J. 1997, 12, 9-19. [CrossRef]

171. Ueguchi-Tanaka, M.; Ashikari, M.; Nakajima, M.; Itoh, H.; Katoh, E.; Kobayashi, M.; Chow, T.Y.; Hsing, Y.I.C.; Kitano, H.; Yamaguchi, I.; et al. GIBBERELLIN INSENSITIVE DWARF1 encodes a soluble receptor for gibberellin. Nature 2005, 437, 693-698. [CrossRef]

172. Sun, T.P. Gibberellin-GID1-DELLA: A Pivotal Regulatory Module for Plant Growth and Development. Plant Physiol. 2010, 154, 567-570. [CrossRef] [PubMed]

173. Zentella, R.; Zhang, Z.L.; Park, M.; Thomas, S.G.; Endo, A.; Murase, K.; Fleet, C.M.; Jikumaru, Y.; Nambara, E.; Kamiya, Y.; et al. Global analysis of DELLA direct targets in early gibberellin signaling in Arabidopsis. Plant Cell 2007, 19, 3037-3057. [CrossRef] [PubMed]

174. Kepczynski, J.; Cembrowska-Lech, D.; Van Staden, J. Necessity of gibberellin for stimulatory effect of KAR(1) on germination of dormant Avena fatua L. caryopses. Acta Physiol. Plant. 2013, 35, 379-387. [CrossRef]

175. Kepczynski, J. Induction of agricultural weed seed germination by smoke and smoke-derived karrikin (KAR(1)), with a particular reference to Avena fatua L. Acta Physiol. Plant. 2018, 40. [CrossRef]

176. de Saint Germain, A.; Ligerot, Y.; Dun, E.A.; Pillot, J.P.; Ross, J.J.; Beveridge, C.A.; Rameau, C. Strigolactones Stimulate Internode Elongation Independently of Gibberellins. Plant Physiol. 2013, 163, 1012-1025. [CrossRef]

177. Bassel, G.W.; Mullen, R.T.; Bewley, J.D. Procera is a putative DELLA mutant in tomato (Solanum lycopersicum): Effects on the seed and vegetative plant. J. Exp. Bot. 2008, 59, 585-593. [CrossRef]

178. Luo, L.; Takahashi, M.; Kameoka, H.; Qin, R.Y.; Shiga, T.; Kanno, Y.; Seo, M.; Ito, M.; Xu, G.H.; Kyozuka, J. Developmental analysis of the early steps in strigolactone-mediated axillary bud dormancy in rice. Plant $\mathrm{J}$. 2019, 97, 1006-1021. [CrossRef]

179. Brun, G.; Thoiron, S.; Braem, L.; Pouvreau, J.B.; Montiel, G.; Lechat, M.M.; Simier, P.; Gevart, K.; Goormachtig, S.; Delavault, P. CYP707As are effectors of karrikin and strigolactone signalling pathways in Arabidopsis thaliana and parasitic plants. Plant Cell Environ. 2019, 42, 2612-2626. [CrossRef]

180. Matilla, A.J. Ethylene in seed formation and germination. Seed Sci. Res. 2000, 10, 111-126. [CrossRef]

181. Sugimoto, Y.; Ali, A.M.; Yabuta, S.; Kinoshita, H.; Inanaga, S.; Itai, A. Germination strategy of Striga hermonthica involves regulation of ethylene biosynthesis. Physiol. Plant 2003, 119, 137-145. [CrossRef]

182. Jackson, M.B.; Parker, C. Induction of Germination by a Strigol Analog Requires Ethylene Action in Striga-Hermonthica but Not in S-Forbesii. J. Plant Physiol. 1991, 138, 383-386. [CrossRef]

183. Zehar, N.; Ingouff, M.; Bouya, D.; Fer, A. Possible involvement of gibberellins and ethylene in Orobanche ramosa germination. Weed Res. 2002, 42, 464-469. [CrossRef] 
184. Rasmussen, A.; Hu, Y.M.; Depaepe, T.; Vandenbussche, F.; Boyer, F.D.; Van Der Straeten, D.; Geelen, D. Ethylene Controls Adventitious Root Initiation Sites in Arabidopsis Hypocotyls Independently of Strigolactones. J. Plant Growth Regul. 2017, 36, 897-911. [CrossRef]

185. Hu, Z.Y.; Yamauchi, T.; Yang, J.H.; Jikumaru, Y.; Tsuchida-Mayama, T.; Ichikawa, H.; Takamure, I.; Nagamura, Y.; Tsutsumi, N.; Yamaguchi, S.; et al. Strigolactone and Cytokinin Act Antagonistically in Regulating Rice Mesocotyl Elongation in Darkness. Plant Cell Physiol. 2014, 55, 30-41. [CrossRef] [PubMed]

186. Koren, D.; Resnick, N.; Gati, E.M.; Belausov, E.; Weininger, S.; Kapulnik, Y.; Koltai, H. Strigolactone signaling in the endodermis is sufficient to restore root responses and involves SHORT HYPOCOTYL 2 (SHY2) activity. New Phytol. 2013, 198, 866-874. [CrossRef]

187. Kulkarni, M.G.; Rengasamy, K.R.R.; Pendota, S.C.; Gruz, J.; Plackova, L.; Novak, O.; Dolezal, K.; Van Staden, J. Bioactive molecules derived from smoke and seaweed Ecklonia maxima showing phytohormone-like activity in Spinacia oleracea L. New Biotechnol. 2019, 48, 83-89. [CrossRef]

188. Aremu, A.O.; Plackova, L.; Novak, O.; Stirk, W.A.; Dolezal, K.; Van Staden, J. Cytokinin profiles in ex vitro acclimatized Eucomis autumnalis plants pre-treated with smoke-derived karrikinolide. Plant Cell Rep. 2016, 35, 227-238. [CrossRef]

189. Du, H.; Huang, F.; Wu, N.; Li, X.H.; Hu, H.H.; Xiong, L.H. Integrative Regulation of Drought Escape through ABA-Dependent and -Independent Pathways in Rice. Mol. Plant 2018, 11, 584-597. [CrossRef]

190. Mostofa, M.G.; Li, W.; Nguyen, K.H.; Fujita, M.; Tran, L.P. Strigolactones in plant adaptation to abiotic stresses: An emerging avenue of plant research. Plant Cell Environ. 2018, 41, 2227-2243. [CrossRef]

191. Lopez-Bucio, J.; Cruz-Ramirez, A.; Herrera-Estrella, L. The role of nutrient availability in regulating root architecture. Curr. Opin. Plant Biol. 2003, 6, 280-287. [CrossRef]

192. Sun, H.W.; Bi, Y.; Tao, J.Y.; Huang, S.J.; Hou, M.M.; Xue, R.; Liang, Z.H.; Gu, P.Y.; Yoneyama, K.; Xie, X.N.; et al. Strigolactones are required for nitric oxide to induce root elongation in response to nitrogen and phosphate deficiencies in rice. Plant Cell Environ. 2016, 39, 1473-1484. [CrossRef] [PubMed]

193. Walton, A.; Stes, E.; Goeminne, G.; Braem, L.; Vuylsteke, M.; Matthys, C.; De Cuyper, C.; Staes, A.; Vandenbussche, J.; Boyer, F.D.; et al. The Response of the Root Proteome to the Synthetic Strigolactone GR24 in Arabidopsis. Mol. Cell. Proteom. 2016, 15, 2744-2755. [CrossRef] [PubMed]

194. Pourcel, L.; Routaboul, J.M.; Cheynier, V.; Lepiniec, L.; Debeaujon, I. Flavonoid oxidation in plants: From biochemical properties to physiological functions. Trends Plant Sci. 2007, 12, 29-36. [CrossRef] [PubMed]

195. Ferreyra, M.L.F.; Rius, S.P.; Casati, P. Flavonoids: Biosynthesis, biological functions, and biotechnological applications. Front. Plant Sci. 2012, 3. [CrossRef]

196. Nakabayashi, R.; Yonekura-Sakakibara, K.; Urano, K.; Suzuki, M.; Yamada, Y.; Nishizawa, T.; Matsuda, F.; Kojima, M.; Sakakibara, H.; Shinozaki, K.; et al. Enhancement of oxidative and drought tolerance in Arabidopsis by overaccumulation of antioxidant flavonoids. Plant J. 2014, 77, 367-379. [CrossRef]

197. Koltai, H. Strigolactones activate different hormonal pathways for regulation of root development in response to phosphate growth conditions. Ann. Bot. 2013, 112, 409-415. [CrossRef]

198. Koltai, H. Cellular events of strigolactone signalling and their crosstalk with auxin in roots. J. Exp. Bot. 2015, 66, 4855-4861. [CrossRef]

199. Marzec, M. Strigolactones and Gibberellins: A New Couple in the Phytohormone World? Trends Plant Sci. 2017, 22, 813-815. [CrossRef]

200. Lantzouni, O.; Klermund, C.; Schwechheimer, C. Largely additive effects of gibberellin and strigolactone on gene expression in Arabidopsis thaliana seedlings. Plant J. 2017, 92, 924-938. [CrossRef]

201. Matusova, R.; Rani, K.; Verstappen, F.W.A.; Franssen, M.C.R.; Beale, M.H.; Bouwmeester, H.J. The strigolactone germination stimulants of the plant-parasitic Striga and Orobanche spp. are derived from the carotenoid pathway. Plant Physiol. 2005, 139, 920-934. [CrossRef] [PubMed]

202. Lopez-Raez, J.A.; Charnikhova, T.; Gomez-Roldan, V.; Matusova, R.; Kohlen, W.; De Vos, R.; Verstappen, F.; Puech-Pages, V.; Becard, G.; Mulder, P.; et al. Tomato strigolactones are derived from carotenoids and their biosynthesis is promoted by phosphate starvation. New Phytol. 2008, 178, 863-874. [CrossRef] [PubMed]

203. Torres-Vera, R.; Garcia, J.M.; Pozo, M.J.; Lopez-Raez, J.A. Do strigolactones contribute to plant defence? Mol. Plant Pathol. 2014, 15, 211-216. [CrossRef] [PubMed] 
204. Marzec, M.; Muszynska, A. In Silico Analysis of the Genes Encoding Proteins that Are Involved in the Biosynthesis of the RMS/MAX/D Pathway Revealed New Roles of Strigolactones in Plants. Int. J. Mol. Sci. 2015, 16, 6757-6782. [CrossRef] [PubMed]

205. Zhuang, L.; Wang, J.; Huang, B. Drought inhibition of tillering in Festuca arundinacea associated with axillary bud development and strigolactone signaling. Environ. Exp. Bot. 2017, 142, 15-23. [CrossRef]

206. Kong, C.-C.; Ren, C.-G.; Li, R.-Z.; Xie, Z.-H.; Wang, J.-P. Hydrogen peroxide and strigolactones signaling are involved in alleviation of salt stress induced by arbuscular mycorrhizal fungus in sesbania cannabina seedlings. J. Plant Growth Regul. 2017, 36, 734-742. [CrossRef]

207. Mackova, H.; Hronkova, M.; Dobra, J.; Tureckova, V.; Novak, O.; Lubovska, Z.; Motyka, V.; Haisel, D.; Hajek, T.; Prasil, I.T.; et al. Enhanced drought and heat stress tolerance of tobacco plants with ectopically enhanced cytokinin oxidase/dehydrogenase gene expression. J. Exp. Bot. 2013, 64, 2805-2815. [CrossRef]

208. Nishiyama, R.; Watanabe, Y.; Fujita, Y.; Le, D.T.; Kojima, M.; Werner, T.; Vankova, R.; Yamaguchi-Shinozaki, K.; Shinozaki, K.; Kakimoto, T.; et al. Analysis of Cytokinin Mutants and Regulation of Cytokinin Metabolic Genes Reveals Important Regulatory Roles of Cytokinins in Drought, Salt and Abscisic Acid Responses, and Abscisic Acid Biosynthesis. Plant Cell 2011, 23, 2169-2183. [CrossRef]

209. Li, W.Q.; Herrera-Estrella, L.; Tran, L.S.P. Do Cytokinins and Strigolactones Crosstalk during Drought Adaptation? Trends Plant Sci. 2019, 24, 669-672. [CrossRef]

210. Lim, P.O.; Kim, H.J.; Nam, H.G. Leaf senescence. Annu. Rev. Plant Biol. 2007, 58, 115-136. [CrossRef]

(C) 2019 by the authors. Licensee MDPI, Basel, Switzerland. This article is an open access article distributed under the terms and conditions of the Creative Commons Attribution (CC BY) license (http://creativecommons.org/licenses/by/4.0/). 